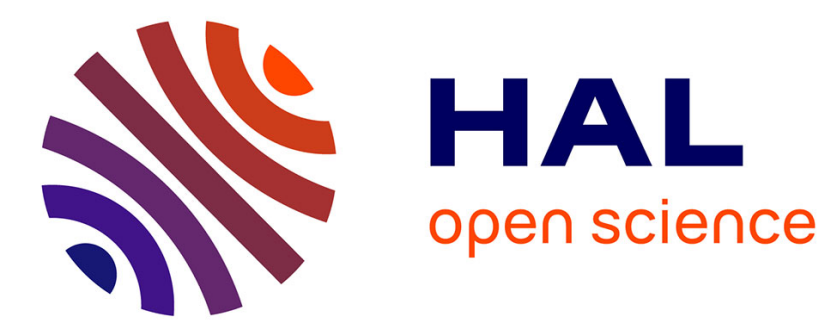

\title{
Ingratiation: Experimental Evidence
}

Stéphane Robin, Agnieszka Rusinowska, Marie Claire Villeval

\section{To cite this version:}

Stéphane Robin, Agnieszka Rusinowska, Marie Claire Villeval. Ingratiation: Experimental Evidence. European Economic Review, 2014, 66, pp.16-38. 10.1016/j.euroecorev.2013.11.005 . halshs00911556

\section{HAL Id: halshs-00911556 https://shs.hal.science/halshs-00911556}

Submitted on 16 Dec 2013

HAL is a multi-disciplinary open access archive for the deposit and dissemination of scientific research documents, whether they are published or not. The documents may come from teaching and research institutions in France or abroad, or from public or private research centers.
L'archive ouverte pluridisciplinaire HAL, est destinée au dépôt et à la diffusion de documents scientifiques de niveau recherche, publiés ou non, émanant des établissements d'enseignement et de recherche français ou étrangers, des laboratoires publics ou privés. 


\title{
Ingratiation: Experimental Evidence
}

\author{
Stéphane Robin, ${ }^{\mathrm{a}}$ Agnieszka Rusinowska, ${ }^{\mathrm{b}}$ Marie Claire Villeval ${ }^{\mathrm{c}}$
}

\begin{abstract}
We investigate experimentally ingratiatory behavior expressed by opinion conformity. Both individuals' performance at a task and their opinions on various topics can be observed before unequal payoffs are assigned by a second mover. In some treatments, first movers can change their opinion after learning that held by the second mover. We find evidence of high ingratiation indices, as opinion conformity is rewarded. However, second movers reward conformity less when it is common knowledge that opinions can be manipulated strategically. Introducing a monetary cost for changing opinion reduces ingratiation. Introducing performance-related pay for the second mover makes ingratiation less rewarding but does not eliminate it completely. Reducing the noise in the measurement of ability has little effect.
\end{abstract}

Keywords: Ingratiation, opinion conformity, favoritism, discrimination, social distance, experiment.

JEL Classification: C92, D03, D86, M51

${ }^{a}$ University of Lyon, F-69007, Lyon, France ; CNRS, GATE Lyon St Etienne, 93, Chemin des Mouilles, 69130 Ecully, France. Email: robin@gate.cnrs.fr

${ }^{\mathrm{b}}$ CES (Centre d'Economie de la Sorbonne), Paris School of Economics - CNRS, 106-112 Bd de l'Hôpital, 75647 Paris, France. Email: agnieszka.rusinowska@univ-paris1.fr

${ }^{c}$ University of Lyon, F-69007, Lyon, France ; CNRS, GATE Lyon St Etienne, 93, Chemin des Mouilles, 69130 Ecully, France. Email: villeval@gate.cnrs.fr

Acknowledgments: The authors are grateful to Jeffrey Carpenter, Gary Charness, Glen Dutcher, Stefano Della Vigna, Seda Ertac, Armin Falk, Urs Fischbacher, Guido Friebel, Michel Grabisch, Alan Kirman, Michael Kosfeld, John Jensenius, Marco Piovesan, Aldo Rustichini, Arthur Schram, Matthias Sutter, and participants at the conferences of the Economic Science Association in Chicago, of the European Association of Labour Economists in Cyprus, of the Society for the Advancement of Economic Theory in Faro, at seminars at the Universities of Bremen, Frankfurt, Innsbrück, Konstanz, Munich, Koc University in Istanbul, at Florida State University at Talahassee, and at the EMIR and MINT workshops in Lyon and Paris. The financial support of ANR (National Research Agency) to the MINT program is gratefully acknowledged (ANR_09-BLAN-0321-01). This research was performed within the framework of the LABEX CORTEX (ANR-11-LABX-0042) of Université de Lyon, within the program "Investissements d'Avenir" (ANR-11-IDEX-007) operated by the French National Research Agency (ANR). 


\section{INTRODUCTION}

This paper studies ingratiatory behavior directed at individuals who have discretion in the assignment of payoffs. Ingratiation can be defined as "strategic behaviors employed by a person to make himself more attractive to another" (Wortman and Linsenmeier, 1977), or as "a strategic attempt to get someone to like you in order to obtain compliance with a request" (Vaughan and Hogg, 2008). ${ }^{1}$ In a work environment, ingratiation occurs when an employee aims to impress his superiors by increasing his attractiveness, particularly when promotions are at stake. Using survey data from Forbes 500 companies, Westphal and Stern (2006) show that managers use interpersonal influence activity as a substitute for elite credentials to obtain boardroom appointments. ${ }^{2}$ Ingratiation can result from various strategies including opinion conformity, self-presentation and other-enhancement. ${ }^{3}$ We focus here on the first strategy.

Ingratiation within organizations has certainly been encouraged by the development of subjective appraisals of employees that may leave the door open to favoritism. Prendergast and Topel (1996) have modeled favoritism as resulting from the unavailability of objective measures of performance and ability. Subjectivity may lead evaluators to reward preferred subordinates arbitrarily. ${ }^{4}$ Bandiera et al. (2009) have shown the importance of social connections, as managers who are paid a fixed wage tend to favor the employees to whom they are socially connected, regardless of their ability. Bramoullé and Goyal (2011) explain, however, that favoritism may exist even without introducing managers' social preferences, as

\footnotetext{
${ }^{1}$ Ingratiation is also thought to be widespread among politicians for the support of voters, citizens for reaching priority access to certain facilities, sellers for encouraging customers to buy, individuals for facilitating mating.

${ }^{2}$ Ingratiation does not necessarily originate in informational asymmetries, in contrast to the influence activities modeled by Milgrom (1988) and Milgrom and Roberts (1988). It also differs from collusion within organizations (Tirole, 1986), as it does not involve bribing the superior. In contrast to the "Yes Men" theory of Prendergast (1993), which provides a rationale for subordinates to conform to their superiors' opinions by reporting what the superiors want to hear about employees' efforts, ingratiation by opinion conformity is not restricted to information that directly influences a firm's profit.

${ }^{3}$ Opinion conformity consists of expressing preferences supporting the opinion held by a target person; selfpresentation is a means of self-promotion; other-enhancement includes flattering (Jones, 1964).

${ }^{4}$ A survey, conducted in U.S. companies with over 1,000 employees, indicates that $84 \%$ of the 302 senior business executives interviewed online report that favoritism exists in their company, and $23 \%$ admit they have practiced it themselves (Gardner, 2011). Favoritism is defined in this survey as: "Preferential treatment of an employee for assignments, credit, opinion, influence, or advancement on the basis of factors that do not directly relate to a person's ability to perform his or her job function, such as background, ideology or gut instincts."
} 
it may allow a social group in which favors are traded to retain more surplus within the group.

Efferson et al. (2008) have shown that in-group favoritism may help heterogeneous people to solve coordination problems. Therefore, on the one hand, favoritism and ingratiation may harm the firm's performance because they pervade the information on which job assignments are made. By distorting incentives, they may also discourage the effort of employees. On the other hand, favoring opinion proximity may be beneficial if it facilitates communication, although it is not certain that this advantage persists if opinions are not sincere.

To the best of our knowledge, no empirical economic study has so far investigated ingratiatory behavior or favoritism based on opinion conformity. ${ }^{5,6}$ A novelty of our paper is that we analyze ingratiation and the influence of opinion proximity on the assignment of payoffs, within the same framework. We provide empirical evidence on strategic opinion conformity in an environment in which individuals compete for a high payoff assignment allocated by an impartial second mover receiving a fixed payoff. ${ }^{7}$ As opinion proximity may be interpreted as a signal of reduced social distance, our study also sheds light on discriminatory processes based on social distance.

Since reliable survey data on ingratiation are hardly available, we have designed a laboratory experiment in which three individuals have to perform a task that signals their ability before a second mover assigns unequal payoffs between the three first movers. In the Baseline treatment, the second mover can obtain information on the individuals' performances at the task and on their opinions about a certain topic before assigning the high

\footnotetext{
${ }^{5}$ Empirical tests of favoritism focus on demographic characteristics (Goldin and Rouse, 2000; Knowles et al., 2001; Fershtman and Gneezy, 2001) or on home bias in sports (Kocher and Sutter, 2004; Garicano et al., 2005) and editing (Laband and Piette, 1994). In addition to Bandiera et al. (2009), recent experimental studies have investigated in-group/out-group discrimination based on personal relations or social distance in trust games (Falk and Zehnder, 2013; Hargreaves Heap and Zizzo, 2009; Brandts and Sola, 2010), bargaining games (Zizzo, 2011), or competition games (Filippin and Guala, 2013; Dutcher, 2011). On social distance, see Akerlof (1997). ${ }^{6}$ In contrast, social psychologists have investigated ingratiatory behaviors more frequently. For meta-analyses, see notably Gordon (1996) and Higgins et al. (2003) and Appelbaum and Hughes (1998) for a survey.

${ }^{7}$ This may apply to bureaucratic organizations where superiors have to rate subordinates and where their own wage does not depend (at least not directly) on the performance of the promoted subordinates. In a broader perspective, the idea was to introduce an impartial third-party like in the theories of justice (see Konow, 2009).
} 
payoff to one of them. Indeed, at the beginning of each session, the players have to report their opinion on various topics. Comparing the opinions of the first and the second movers gives a metric of their proximity. This design allows us to measure the respective weight of relative performance and opinion proximity in the assignment of unequal payoffs when no incentive scheme guides the second mover's choice. A meritocratic second mover is likely to value more the first dimension, while an opinion-oriented second mover may value more the second dimension.

In the Baseline, first movers cannot change their opinion after learning that of the second mover. In contrast, in the Ingratiation treatment they have the option of changing privately their opinion before the second mover can ask about it. We exploit this change to identify whether second movers are expected to reward opinion proximity and whether their behavior differs when it is common knowledge that proximity may result from ingratiation.

Opinion conformity is, however, not always strategic. ${ }^{8}$ To disentangle ingratiation and a taste for conformity or social learning, a Random treatment has been designed. The assignment of payoffs is now random and the second mover passive, but first movers are still allowed to change their opinions. The comparison with the Ingratiation treatments measures the importance of strategic conformity.

We have designed three additional treatments to test the sensitiveness of ingratiation to three interventions. First, we test whether ingratiation resists the introduction of a monetary cost for changing one's opinion. Second, we test the sensitiveness of ingratiation to a reduction of the noise in the measure of individuals' relative ability. Indeed, if this measure becomes less noisy, the assignment of payoffs may rely less on opinion proximity, making

\footnotetext{
${ }^{8}$ In psychology, conformity is motivated by the search for social approval (Asch, 1951; Cialdini and Goldstein, 2004). Neuroscientists have shown that the brain analyzes a deviation from the group opinion as a punishment (Berns, 2008; Klucharev et al., 2009). Economists give three explanations for conformity. Herding behavior (Banerjee, 1992; Scharfstein and Stein, 1990) and informational cascades (Bikhchandani et al., 1992) result from informational deficits. Conformity results from the impairment of status in case of departure from a social norm (Akerlof, 1980; Jones, 1984; Bernheim, 1994). It creates mutual positive externalities (Katz and Shapiro, 1986).
} 
ingratiation less rewarding. Third, we introduce incentives that tie the second mover's compensation to the first movers' performances. We expect reciprocal second movers to reward less (or no longer) opinion proximity and thus ingratiation to decrease (or disappear).

Our results show that a majority of individuals are willing to change their opinion after learning the second mover's opinion. We find evidence of both a pure taste for conformity and strategic conformity. Not all first movers change their opinion, however, which supports the idea that changing opinion strategically entails some moral costs. Indeed, ingratiation is also less likely when the initially reported strength of opinion is higher. In contrast, ingratiation is more likely when opinions are related to a highly debated issue although the moral cost of changing this opinion is probably higher, which suggests that ingratiation is not only acquisitive (driven by the desire to access resources) but also protective (motivated by the willingness to prevent sanctions in case of disagreement) (Jones, 1964).

Ingratiation does not disappear over time because opinion proximity is rewarded, although second movers should be indifferent between first movers in the absence of incentives. If a majority of them behave in accordance with a meritocratic principle and assign the high payoff to the most able individual, a shorter social distance increases the likelihood of getting the high payoff. Second movers discriminate against those who express more distant opinions. We interpret this result in terms of value homophily. This notion has been conceptualized by Lazarsfeld and Merton (1954) and defined as the tendency to associate with other individuals who think in similar ways. Consistently, knowing that first movers can conform strategically reduces the influence of opinion proximity.

Imposing a monetary cost for changing opinion discourages ingratiation. Introducing performance-related incentives for the second movers is the policy intervention that increases the most the role of relative ability in the assignment of a promotion, relative to opinion proximity. This result is consistent with Bandiera et al. (2009) who find that managerial 
performance pay increases the productivity of high ability employees, especially those who have no connection with the manager. However, incentives eliminate neither ingratiation, nor discrimination in favor of similarly-oriented individuals. Finally, reducing the noise in the measure of ability does not increase the chance of the ablest individual to get the high payoff.

The remainder of this paper is organized as follows. Section 2 presents the experimental design and our behavioral hypotheses. Section 3 displays the results of the experiment while Section 4 discusses these results and concludes.

\section{EXPERIMENTAL DESIGN AND BEHAVIORAL HYPOTHESES}

We designed a game with three individuals who have to perform a task and one player who has to assign unequal payoffs between the three first movers. The second mover can get access to two sets of information before assigning the payoffs: the performance and the opinions of the first movers on various topics.

\subsection{Elicitation of opinions}

In the first part of each session, we elicited the players' opinions on four topics displayed in random order. Two topics are related to tastes and two others are related to highly debated issues. After looking at a naïve art painting and listening to a piece of reggae music, the players had to rate their taste for the painting and the music on a rating scale ranging from 1 ("I hate it") to 100 ("I adore it"). They also had to rate their opinion on two statements: "One should introduce a carbon tax to change the course of global warming" and "One should regularize illegal immigrants", between 1 ("extremely unfavorable") and 100 ("extremely favorable"). Players were informed that their responses were anonymous but would be used in the next parts of the session with no further information. Since we expect that ingratiation is negatively correlated with the strength of one's opinion (because the moral cost of ingratiation is higher if one values more this opinion), they had to indicate the importance of 
each response on a Likert-type scale between 1 ("I could have answered completely differently") and 10 ("my answer represents a lot to me"). Answers were not incentivized.

\subsection{Main treatments}

Our experiment included three treatments called Baseline, Ingratiation, and Random.

The Baseline treatment consists of 12 periods. Each period includes three stages. In the first stage, groups of four were formed randomly, including three first movers who have to perform a task and one second mover who has to assign payoffs. Roles were kept constant throughout the session. First movers were informed about their second mover's opinion on one randomly selected topic, but not on the other first movers' opinions.

In the second stage, the first movers had to answer two questions of a quiz on general knowledge. Each first mover was only informed of his performance, that is his own number of correct answers. It was common information that the random draw of questions was independently and identically distributed for each first mover, which is equivalent to introducing an idiosyncratic random term in the performance. This performance is not intended to measure effort but ability or knowledge. ${ }^{9}$

In the third stage, the second mover had to assign payoffs to the first movers, namely one payoff of 10 points (with 18 points $=€ 1$ ) and two payoffs of 5 points. To determine whether the perspective of a higher payoff motivates ingratiation, we force the second mover to assign unequal payoffs. This allows us to identify the relative weight of meritocracy (rewarding ability) and social distance (rewarding opinion proximity) in the judgment on deservedness. In order not to force the second mover's attention on any information, two buttons were available on his computer screen. One button was for asking information about the three first movers' performances and the other one for asking the three first movers' opinions on the

\footnotetext{
${ }^{9}$ The difficulty of the items in the quiz is variable. Therefore, luck matters. However, subjects received many questions and so, on average they were exposed to the same degree of difficulty as were the other subjects. The presence of luck does not seem to have reduced the players' concentration on the task. Intrinsic motivation is shown by the fact that mean performances are similar in the treatments with extrinsic incentives (Baseline and Ingratiation treatment) and without extrinsic incentives (Random treatment).
} 
issue selected in the first stage. Each button was randomly disposed on the left or the right of the screen. Second movers could press no button, one or two buttons. Information was free. To create impartiality, the second mover was paid a fixed payoff of 12 points. A fixed payoff allows us to observe the natural inclination for meritocracy or for opinion proximity relative to a random assignment of payoffs. Incentives are introduced in an additional treatment to study how they distort this inclination.

At the end of each period, first movers learned of their own payoff, but not the (absolute or relative) opinion and performance of the first mover who got the high payoff. Groups were re-matched in the next period. Using a stranger matching protocol eliminates players trying to build reciprocal relationships based on favoritism and favor rendering.

There is only one difference between the Ingratiation treatment and the Baseline: first movers were allowed to change their initial opinion before it was made available to the second mover and after receiving a feedback on their performance. The second mover knew that first movers could modify their opinion but she only observed the reported opinions without knowing whether they had been changed or not. As before, first movers did not receive any information about other first movers' opinions or performances. This treatment allowed us to determine the importance of ingratiation and its relationship with performance, the topic of opinion, and the strength of opinions. Comparing the Baseline and the Ingratiation treatments indicates whether the respective weights of relative performances and opinions differ when second movers know that opinions can be manipulated strategically.

First movers may change their opinion strategically but also because they like conforming to the opinion of a high status person or because they are uncertain about their opinion. To disentangle these strategic and non-strategic reasons, in the Random treatment first movers can still change their opinion but second movers are now passive: first movers' payoffs are assigned randomly. In this context, we assume that a change in opinion is driven 
by a taste for conformity or by social learning, but it is not strategic. Comparing Ingratiation and Random treatments indicates to what extent opinion conformity is strategic. In this treatment, subjects without any intrinsic motivation should not exert effort at all.

Each participant played in two treatments (i.e. two times 12 periods): the Ingratiation treatment and either the Baseline or the Random treatment. The order of treatments was counterbalanced across sessions.

\subsection{Policy interventions}

We tested in new treatments the sensitiveness of ingratiation to three policy interventions: a reduction of the noise in the measurement of relative ability; the introduction of a monetary cost for changing opinion; and the introduction of incentives for second movers.

In the Baseline-No Noise and Ingratiation-No Noise treatments, we increased the precision of relative performance measures. The three first movers received the same four questions instead of two, which reduced the role of idiosyncratic luck in performances. A comparison with the original treatments indicates whether, when performances are more informative of ability, opinion conformity is less rewarded than before and thus ingratiation is reduced.

The Ingratiation-Cost and Random-Cost treatments introduced a fixed cost of 1 point for changing one's opinion regardless of the size of the change (it corresponds to $20 \%$ of the low payoff and $10 \%$ of the high payoff). Comparing these treatments with the original ones indicates whether ingratiation is cost-sensitive but also whether opinion proximity is rewarded more if less ingratiation is expected.

In the Baseline-Incentives and Ingratiation-Incentives treatments, we tied the second mover's payoff to the sum of the three first movers' performances. The second mover's payoff function becomes: $w_{m}=w_{0}+\gamma \sum_{k} y_{k}=10+0.5 \sum_{k=1}^{3} y_{k}$ 
where $w_{m}$ denotes the second mover's payoff. The parameter $\gamma \geq 0$ captures the strength of incentives and $y_{k}$ indicates the performance of first mover $k$. We tested whether, by making relative abilities more salient in the payoff function, these incentives lead second movers to reward relatively less opinion conformity and consequently reduce ingratiation. Indeed, if reciprocity matters, the second mover may be willing to reward the first mover who has got the highest performance because this first mover contributes more to the second mover's payoff. ${ }^{10}$

\subsection{Behavioral hypotheses}

It is assumed that before assigning the payoffs, the second mover can observe first movers' performance at a task as well as their opinions on some issues. The performance of first mover $k$ is given by

$$
y_{k}=e_{k}+\varepsilon_{k}
$$

where $e_{k}$ measures the effort exerted by $k$ or his skill, and $\varepsilon_{k}$ is an idiosyncratic random or luck component.

Extending the framework of favoritism studied in Prendergast and Topel (1996) in which a manager observes only performance, we write the second mover's utility as follows:

$$
u_{m}=w_{m}+\alpha w_{d i s t}+\beta w_{p e r f}
$$

where $w_{\text {dist }}$ denotes the payoff of the first mover with the lowest distance between his opinion and the opinion of the second mover, and $w_{\text {perf }}$ denotes the payoff of the first mover with the highest performance. $\alpha \geq 0$ and $\beta \geq 0$ measure the intensity of the second mover's preference for one of the two types of first movers, respectively. Any relationship between $\alpha$ and $\beta$ is allowed in the model, and the existing relationship between them determines the type of the second mover. More precisely, $\alpha>\beta$ characterizes a second mover who values more opinion

\footnotetext{
${ }^{10}$ An alternative would be to link the second mover's payoff to the performance of the sole first mover who receives the high payoff. This would allow us to measure how much money second movers are willing to forego to favor opinion conformity instead of ability. Our less direct but perhaps more realistic payoff function enabled us to test whether making the reference to performance more salient suffices to reduce favoritism.
} 
proximity, with the particular case of the opinion-oriented second mover when $\beta=0$. Similarly, $\beta>\alpha$ describes a second mover who favors more ability. This second mover is called a meritocratic second mover when $\alpha=0$. The case when $\alpha=\beta$ means that the second mover weighs equally both dimensions. An indifferent second mover does not pay attention to either performance or opinion and is characterized by $\alpha=\beta=0$.

The degree of ingratiation by opinion conformity is measured by the so-called ingratiation index, which is defined similarly to the influence index in the framework of influence in a social network (Grabisch and Rusinowska, 2009, 2010). Let $d_{i n i}^{k}$ denote the distance between the initial opinion of the first mover $k$ and the opinion of the second mover, and $d_{f i n}^{k}$ be the distance between the final (reported) opinion of the first mover and the opinion of the second mover. For all $d_{i n i}^{k} \neq 0$ and $d_{i n i}^{k} \geq d_{f i n}^{k}$ we define the individual's ingratiation index by

$$
I_{k}=\frac{d_{i n i}^{k}-d_{f i n}^{k}}{d_{i n i}^{k}} \in[0,1]
$$

The higher $I_{k}$ is, the stronger is the first mover's ingratiation behavior. $I_{k}=0$ reports no ingratiation behavior and $I_{k}=1$ corresponds to perfect ingratiation. The cost function of ingratiation is given by

$$
C_{k}\left(I_{k}\right)=\left(c_{k}+c_{k}^{m o}(s)\right) I_{k}
$$

where $c_{k}$ is a monetary cost (equal to 0 in all treatments but one). $c_{k}^{m o}(s)$ denotes the moral cost of ingratiation which we assume to be an increasing function of the strength $s$ of the opinion, i.e., the more important his personal opinion on a given topic is to the individual, the higher is his moral cost of ingratiation. ${ }^{11}$ Individual $k$ 's utility is defined as follows:

\footnotetext{
${ }^{11}$ The moral cost of ingratiation could be higher if ingratiation was made visible to the other first movers because it could generate social disapproval. Here, we assume that expressing a different opinion from that initially reported entails a moral cost that increases in the strength of the initial opinion because of self-image concerns. Individuals with no self-image may have no moral cost of ingratiation.
} 
$u_{k}\left(f_{I_{k}}^{k}(\alpha, \beta)\right)=\left\{\begin{array}{cc}10-C_{k}\left(I_{k}\right)-c\left(e_{k}\right) & \text { if the second mover gives the high payoff to first mover } k \\ 5-C_{k}\left(I_{k}\right)-c\left(e_{k}\right) & \text { if the second mover gives the low payoff to first mover } k\end{array}\right.$ with the act denoted by $f_{I_{k}}^{k}$ and the cost of effort exerted by the first mover denoted by $\mathrm{c}\left(e_{k}\right)$.

If the individual $k$ faces a second mover who favors opinion proximity, $\alpha \neq 0$, then the probability to get the high payoff increases with a higher $I_{k}$. The first mover $k$ has to choose his ingratiation index $I_{k}$, or equivalently, the distance $d_{\text {fin }}^{k}$ between his final (reported) opinion and the opinion of the second mover, without knowing the type of his second mover (his $\alpha$ and $\beta$ ). Consequently, the first mover faces a problem of decision under uncertainty. Let $\pi_{k}\left(y_{k}, d_{f i n}^{k}\right)$ denote the expected payoff function to the first mover $k$. Given his performance, the first mover $k$ chooses the ingratiation index $I_{k}$ that maximizes his expected utility:

$$
\arg \max _{I_{k}} E_{\alpha, \beta}\left(u_{k}\left(f_{I_{k}}^{k}(\alpha, \beta)\right)\right)
$$

In other words, given his performance $y_{k}=e_{k}+\varepsilon_{k}, k$ chooses the distance $d_{\text {fin }}^{k}$ equal to

$$
\arg \max _{d_{f i n}^{k}}\left(\pi_{k}\left(y_{k}, d_{f i n}^{k}\right)-C_{k}\left(I_{k}\right)-c\left(e_{k}\right)\right)
$$

We can prove the following result:

\section{Proposition 1}

Let $d_{i n i}^{k} \neq 0$ and the expected payoff $\pi_{k}\left(y_{k}, d_{f i n}^{k}\right)$ be decreasing in $d_{f i n}^{k}$. Then it is optimal for the first mover $k$ to ingratiate if the costs of ingratiation are sufficiently low.

\section{Proof}

Consider a first mover $k$ such that $d_{i n i}^{k} \neq 0$ and assume that $\pi_{k}\left(y_{k}, d_{\text {fin }}^{k}\right)$ is decreasing in $d_{f i n}^{k}$. The ingratiation index corresponding to $d_{f i n}^{k}=d_{i n i}^{k}$ is equal to 0 by definition of $I_{k}$, and therefore its cost is $C_{k}(0)=0$. Consider an arbitrary $\widetilde{d}_{f i m}^{k}$ such that $\widetilde{d}_{f i n}^{k}<d_{i n i}^{k}$. Let the ingratiation index corresponding to such $\tilde{d}_{f i n}^{k}$ be denoted by $\tilde{I}_{k}$. Suppose that 
$C_{k}\left(\widetilde{I}_{k}\right)<\pi_{k}\left(\tilde{y}_{k}, \widetilde{d}_{f i n}^{k}\right)-\pi_{k}\left(\widetilde{y}_{k}, d_{i n i}^{k}\right)$, where $\tilde{y}_{k}$ is the performance of $k$. Since the expected payoff is weakly decreasing in the reported distance, the right hand side of the inequality is positive. We have $\pi_{k}\left(\widetilde{y}_{k}, \widetilde{d}_{f i n}^{k}\right)-c\left(\widetilde{e}_{k}\right)-C_{k}\left(\widetilde{I}_{k}\right)>\pi_{k}\left(\widetilde{y}_{k}, d_{i n i}^{k}\right)-c\left(\widetilde{e}_{k}\right)-C_{k}(0)$, which means that it is more optimal to the first mover $k$ to ingratiate than to report the initial opinion.

Based on Proposition 1, we can derive the following hypothesis on the first movers' behavior in the experimental treatments:

Hypothesis 1: Provided the costs of ingratiation are sufficiently low (or even null if the individuals are pure money-maximizers with no self-image concern), the individual should report opinions that reduce the distance in opinion with the second mover. The ingratiation index should be higher in the Ingratiation treatment than in the Random treatment.

Furthermore, we can show the following:

\section{Proposition 2}

Increasing the costs of ingratiation, in particular, the strength of the opinion, decreases ingratiation.

\section{Proof}

Let $\widetilde{I}_{k}$ and $\bar{I}_{k}$ be the optimal ingratiation indices corresponding to the monetary and moral costs $\widetilde{c}=\widetilde{c}_{k}+\widetilde{c}_{k}^{m o}(\widetilde{s})$ and $\bar{c}=\bar{c}_{k}+\bar{c}_{k}^{m o}(\bar{s})$, respectively, where $\widetilde{c}<\bar{c}$. Let $x=\bar{c}-\widetilde{c}>0$.

We have then:

$\pi_{k}\left(y_{k}, \widetilde{d}_{f i n}^{k}\right)-\widetilde{c} \widetilde{I}_{k} \geq \pi_{k}\left(y_{k}, \bar{d}_{f i n}^{k}\right)-\widetilde{c} \bar{I}_{k}$ and $\pi_{k}\left(y_{k}, \bar{d}_{f i n}^{k}\right)-(x+\widetilde{c}) \bar{I}_{k} \geq \pi_{k}\left(y_{k}, \widetilde{d}_{f i n}^{k}\right)-(x+\widetilde{c}) \widetilde{I}_{k}$ and therefore $\widetilde{I}_{k} \geq \bar{I}_{k}$.

From Proposition 2, the following behavioral hypothesis can be derived:

Hypothesis 2: Increasing its monetary or moral costs decreases ingratiation. The ingratiation index should be lower for the players who report stronger opinions and it should be lower in the Ingratiation-Cost treatment than in the initial Ingratiation treatment.

Moreover, we show the following result: 


\section{Proposition 3}

Let $d_{i n i}^{k} \neq 0$ and the expected payoff $\pi_{k}\left(y_{k}, d_{f i n}^{k}\right)$ be weakly increasing in $y_{k}$. Moreover, let $\pi_{k}$ be differentiable and its derivative $\frac{\partial \pi_{k}}{\partial y_{k}}$ with respect to $y_{k}$ be weakly increasing in $d_{f i n}^{k}$ meaning that the smaller is the final distance between opinions, the lower is the marginal impact of effort on the first mover's expected payoff. Then increasing the effort weakly decreases ingratiation.

\section{Proof}

Consider two performance levels $\tilde{y}_{k}$ and $\bar{y}_{k}$, where $\tilde{y}_{k}<\bar{y}_{k}$. Let $\widetilde{I}_{k}$ and $\bar{I}_{k}$ be the corresponding optimal ingratiation indices. Let $c=c_{k}+c_{k}^{m o}(s)$. We have

$$
\begin{aligned}
& \pi_{k}\left(\tilde{y}_{k}, \widetilde{d}_{f i n}^{k}\right)-c \widetilde{I}_{k} \geq \pi_{k}\left(\tilde{y}_{k}, \bar{d}_{f i n}^{k}\right)-c \bar{I}_{k} \text { and } \pi_{k}\left(\bar{y}_{k}, \bar{d}_{f i n}^{k}\right)-c \bar{I}_{k} \geq \pi_{k}\left(\bar{y}_{k}, \tilde{d}_{f i n}^{k}\right)-c \widetilde{I}_{k}, \text { and therefore } \\
& \pi_{k}\left(\bar{y}_{k}, \bar{d}_{f i n}^{k}\right)-\pi_{k}\left(\tilde{y}_{k}, \bar{d}_{f i n}^{k}\right) \geq \pi_{k}\left(\bar{y}_{k}, \widetilde{d}_{f i n}^{k}\right)-\pi_{k}\left(\tilde{y}_{k}, \widetilde{d}_{f i n}^{k}\right) \geq 0 . \text { Hence, as } \frac{\partial \pi_{k}}{\partial y_{k}} \text { is weakly increasing }
\end{aligned}
$$

in $d_{f i n}^{k}$, we have $\bar{d}_{f i n}^{k} \geq \widetilde{d}_{f i n}^{k}$, and therefore $\bar{I}_{k} \leq \widetilde{I}_{k}$.

Based on Proposition 3, we express the following behavioral hypothesis for first movers in the experiment:

Hypothesis 3: Increasing the performance decreases the ingratiation index.

On the second mover's side, as we allow for any relation between $\alpha \geq 0$ and $\beta \geq 0$, we get immediately the following:

\section{Proposition 4}

There is a coexistence of meritocratic, opinion-oriented and indifferent second movers.

In the absence of incentives, rational players should assign payoffs randomly. However, we are interested in observing if both opinion-oriented and meritocratic second movers exist in reality, i.e., if both $\alpha>0$ and $\beta>0$ are identified in the experiment, and in which proportion. Consequently, based on Proposition 4, we express the following hypothesis: 
Hypothesis 4: We can observe meritocratic, opinion-oriented and indifferent second movers.

We make two assumptions on second mover's preference:

(A) Introducing the possibility of ingratiation does not increase $\alpha$.

(B) Improving the accuracy of the relative performance measure and introducing performance pay for second mover do not decrease $\beta$.

These assumptions on $\alpha$ and $\beta$ have natural justifications. We can expect that the intensity of the preference for opinion proximity should be lower (or at least not higher) when the second mover knows that first movers can change their opinion because these opinions are probably less sincere. We can also expect that the intensity of the preference for performance should be higher (or at least not lower) when the accuracy of measuring relative performance is improved, as the difference in relative performance between first movers now depends more on effort and skill and less on personal luck. Similarly, if we link the second mover's payoff to the performance of first movers, then the second mover should not focus less on the performances than before.

Related directly to assumption (A), the following hypothesis will be tested in the experiment:

Hypothesis 5: Knowing the possibility of opinion changes in the Ingratiation treatment decreases the weight of opinion proximity in the assignment of the high payoff compared with the Baseline.

Except if second movers assign payoffs randomly, in the Baseline-No Noise and the Ingratiation-No Noise treatments, the reduction of the noise in the measure of relative ability may increase the weight of relative performances in the assignment of payoffs compared with the initial treatments. The introduction of incentives in the Baseline-Incentive and the Ingratiation-Incentive treatments could also lead second movers to reward opinion proximity less than in the initial treatments. Second movers may indeed be willing to reciprocate a player with a higher performance because this player contributes more to his own payoff. In 
contrast, the introduction of a cost for changing one's opinion in the Ingratiation-Cost treatment may reduce the initial difference between the Baseline and the Ingratiation treatments, as opinions are more likely to be unchanged and therefore, more truthful.

In the experiment, the following hypotheses will also be tested:

Hypothesis 6: A less noisy measure of relative performances and the introduction of incentives decrease the weight of opinion proximity in the assignment of payoffs compared with the initial treatments. Introducing a cost for changing opinion increases the weight of opinion proximity in the assignment of the high payoff compared with the initial Incentive treatment, as opinion proximity is less likely to result from ingratiation.

Hypothesis 7: Consequently, when performances are more informative of ability or when second mover's pay is tied to first movers' performance, ingratiation is reduced as opinion proximity is less rewarded than in the initial Ingratiation treatment.

\subsection{Procedures}

The experiment was computerized, using the REGATE-NG software. 29 sessions were conducted at the laboratory of the Groupe d'Analyse et de Théorie Economique (GATE), Lyon, France, involving 500 undergraduate students from the local Engineering and Business schools invited via the ORSEE software (Greiner, 2004). Table A1 in Appendix indicates the number of participants and the treatments played in each session.

Upon arrival, the participants were randomly assigned to a terminal by drawing a tag from a bag. Instructions for the elicitation of opinions were distributed and read aloud (see Appendix 1). After all of them expressed their opinions on the four issues, instructions were distributed for the next part. After checking individually the understanding of the instructions by means of a questionnaire, roles were assigned and participants played the 12 periods of a given treatment with a random re-matching of groups after each period. Then, the instructions for a second treatment were distributed and they played 12 periods of the new treatment.

At the end of the session, the payoffs of all the periods were added up and converted into euros for payment in cash and in private. Sessions lasted on average 75 minutes and participants earned $€ 14.78$ on average, including a show-up fee of $€ 4$. 


\section{RESULTS}

In this section, we first analyze ingratiatory behavior. Then we study whether and by how much opinion conformity matters relative to ability in the assignment of payoffs. In a final sub-section we report the results of the policy interventions.

\subsection{Ingratiatory behavior}

To measure opinion conformity and ingratiation, we compare the initial distance between the second mover's and the first mover's opinions expressed preliminarily and the final distance between opinions after first movers can change opinion. Table 1 reports summary statistics for each treatment indicating, for the cases in which initial opinions differ, the number of changes in opinions in each direction, the number of observations with perfect or almost perfect ingratiation, and the mean ingratiation index. Perfect ingratiation indicates a change in opinion designed to match exactly the second mover's opinion; almost perfect ingratiation corresponds to the cases in which the initial distance is higher than 2 and the final distance does not exceed 2. The index is calculated as the difference between the initial distance and the final distance, divided by the initial distance. It excludes cases in which the final distance exceeds the initial distance, which by definition does not correspond to ingratiation.

Table 1. Summary statistics

\begin{tabular}{|c|c|c|c|}
\hline Treatments & Baseline & Ingratiation & Random \\
\hline $\begin{array}{l}\text { Same initial opinion as the second } \\
\text { mover's }\end{array}$ & $65(4.75 \%)$ & $130(4.63 \%)^{\mathrm{ns}}$ & $74(5.14 \%)^{\mathrm{ns}}$ \\
\hline Different initial opinion & $1303(95.25 \%)$ & $2678(95.37 \%)^{\mathrm{ns}}$ & $1366(94.86 \%)^{\mathrm{ns}}$ \\
\hline Total number of observations & $1368(100 \%)$ & $2808(100 \%)$ & $1440(100 \%)$ \\
\hline \multicolumn{4}{|c|}{ Sub-sample of observations with a different initial opinion } \\
\hline \multicolumn{4}{|l|}{ Change between final and initial distance } \\
\hline - Increased distance & - & $167(6.24 \%)$ & $116(8.49 \%) * *$ \\
\hline - Same distance & $1303(100 \%)$ & $995(37.15 \%)$ & $819(59.96 \%)^{*}$ \\
\hline - Decreased distance & - & $1516(56.61 \%)$ & $431(31.55 \%)^{* * *}$ \\
\hline Total & $1303(100 \%)$ & $2678(100 \%)$ & $1366(100 \%)$ \\
\hline Perfect ingratiation (same final opinion) & - & $301(11.24 \%)$ & $63(4.61 \%)^{\mathrm{ns}}$ \\
\hline Almost perfect ingratiation (same $+/-2)$ & - & $477(18.57 \%)$ & $103(7.72 \%)^{*}$ \\
\hline Mean ingratiation index & - & $0.42(0.26)$ & $0.19(0.19)^{* * *}$ \\
\hline \multicolumn{4}{|c|}{$\begin{array}{l}\text { Note: The Table reports the significance of two-tailed two-sample tests of proportion comparing, in the upper } \\
\text { part of the Table, each of the Ingratiation and Random treatments with the Baseline, and in the other cases, the } \\
\text { Random treatment with the Ingratiation treatment. The comparison of ingratiation indices in the last row of the } \\
\text { Table is based on a two-tailed Mann-Whitney test (M-W, hereafter). All the tests reported in the paper are }\end{array}$} \\
\hline
\end{tabular}


conducted only on the first period when all observations are still independent. ${ }^{\text {ns }}$ indicates no significance and *, $* *$, and $* * *$ indicate significance at the $10 \%, 5 \%$ and $1 \%$ level, respectively.

Table 1 shows that in the Ingratiation treatment slightly more than one third of the first movers keep the same opinion after learning that it differs from that of the second mover, while $56.61 \%$ of the first movers conform with the second mover's opinion and $11.24 \%$ even match the second mover's opinion perfectly. Most of this behavior is strategic, as in the Random treatment less than one third of the first movers reduce the distance in opinions and perfect conformism represents only $4.61 \%$ of the observations. As a complement, Figure 1 represents the initial difference between the second and the first mover's opinions on the $x$ axis, and the final difference between opinions on the $y$-axis, for each period of the game and for the Ingratiation and the Random treatments.

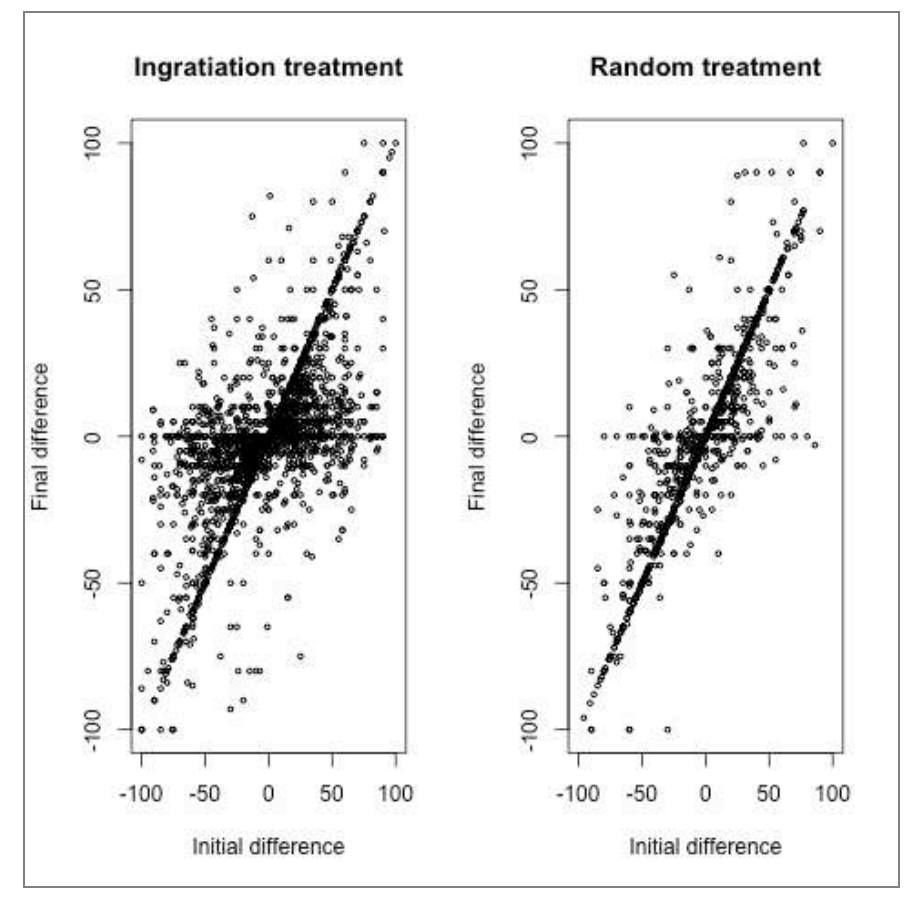

Fig. 1. Distribution of initial and final differences between the second mover's and first mover's opinions

Figure 1 identifies four situations. The first one corresponds to the cases in which individuals do not change opinion. This is represented by the diagonal including the point $(0,0)$ where the first and the second movers share the same initial opinion. A second situation is represented by the few dots located below (above) the diagonal, when the initial difference 
is negative (positive): individuals increase distance with the second mover, which can be seen as anti-conformism (this is outside the scope of this study). Third, the dots on the horizontal line corresponding to a final difference of zero indicate that the first and second movers share the same opinion at the end. When the initial difference is not equal to zero, this reveals perfect ingratiation or perfect conformism. Fourth, almost all the other cases correspond to incomplete ingratiation or conformism. Many individuals change opinion in the Ingratiation treatment, while observations lie more on the diagonal in the Random treatment.

We also find evidence of heterogeneity among the players in terms of consistency of behavior over time: some people do not like to change their statements, while others have no reluctance to be inconsistent in their opinions. Our indicator of consistency is the distribution of first movers according to the number of times they have changed their opinion in the Ingratiation treatment to conform to the second mover's opinion $(\mathrm{N}=234)$. Each topic is presented three times in a sequence, so individuals may change their opinion between 0 and 3 times. We find that when the opinion is about the migration topic, $15.38 \%$ of the 234 subjects in the Ingratiation treatment never changed opinion; $21.80 \%$ changed opinion once, $31.62 \%$ changed it twice and $31.20 \%$ changed it systematically. For the carbon tax statement, these percentages are $23.50 \%, 26.07 \%, 23.93 \%$ and $26.50 \%$, respectively. For the music statement, they are $26.50 \%, 23.50 \%, 23.50 \%$ and $26.50 \%$. Finally, for the painting statement, they are $19.66 \%, 24.79 \%, 25.64 \%$ and $29.91 \%$. These percentages suggest that the volatility in opinion is higher when opinions are about a highly-debated topic.

Next, we analyze the determinants of ingratiation. We estimate multinomial Logit models of the probability for a first mover to increase, keep constant or decrease the distance in opinion with the second mover. The reference category is when the first mover does not modify his initial opinion. We use these models to predict the probability of each of the different possible outcomes since the dependent variable is categorical and can take three 
values that cannot be ordered in a meaningful way. Robust standard errors are clustered at the first mover level to adjust for possible correlation across time. Indeed, since each participant is observed 24 times, the error terms may not be independently and identically distributed, which introduces heteroskedasticity. Clustering standard errors can correct for this possible bias. In Model (1), we pool the data from the Ingratiation and Random treatments and include a dummy variable for the Ingratiation treatment in the independent variables. Model (2) is for the Ingratiation treatment and Model (3) for the Random treatment.

The independent variables include the performance, as ingratiation may be more likely when first movers were not able to answer the quiz. ${ }^{12}$ Regarding opinions, we include the difference between the second mover's and the first mover's initial opinion and its squared value to allow for non-linearity, and the strength of the opinion reported in the preliminary part. We allow ingratiation to differ according to the topic of opinion, by including a dummy variable for each topic (with music as the reference category). To measure whether the ordinal position of the first mover's opinion relative to that of the second mover matters, we include "negative initial difference" variables for the immigration and carbon tax statements indicating whether the first mover's policy opinion was less "conservative" than the second mover's one. We finally control for the order between treatments (with a dummy variable equal to 1 when the Ingratiation treatment was played first), the period in the treatment and the first mover's gender, and we include session dummies.

Table 2 reports only the marginal effects for the probability of decreasing the distance with the second mover's opinion since only this case corresponds to ingratiation.

\footnotetext{
${ }^{12}$ We checked preliminarily that performances do not depend on the initial distance in opinion by means of an OLS model with robust standard errors clustered at the first mover's level, in which the independent variables include dummy variables for each treatment, the distance in opinions interacted with each topic, the first mover's gender and age, the period, the order of treatments and session dummies. The same model was estimated on each treatment separately. The opinion variables were significant in no regression.
} 
Table 2. Determinants of the probability of decreasing the distance in opinion with the second mover - Multinomial Logit models with robust standard errors clustered at the first mover level

\begin{tabular}{|c|c|c|c|}
\hline $\begin{array}{l}\text { Ref. = no change in } \\
\text { distance }\end{array}$ & $\begin{array}{c}\text { Ingratiation and } \\
\text { Random treatments (1) }\end{array}$ & $\begin{array}{l}\text { Ingratiation } \\
\text { treatment (2) }\end{array}$ & $\begin{array}{l}\text { Random treatment } \\
\text { (3) }\end{array}$ \\
\hline Ingratiation treatment & $0.268 * * *(0.030)$ & - & - \\
\hline Performance & $0.007(0.013)$ & $0.002(0.015)$ & $0.006(0.020)$ \\
\hline $\begin{array}{ll}\text { Initial } & \text { opinion } \\
\text { difference } & \end{array}$ & $0.022 * * *(0.002)$ & $0.026^{* * *}(0.002)$ & $0.012 * * *(0.003)$ \\
\hline $\begin{array}{l}\text { Squared initial opinion } \\
\text { differ. }\end{array}$ & $-0.0002 * * *(<0.001)$ & $-0.0002 * * *(<0.001)$ & $-0.0001 * * *(<0.001)$ \\
\hline $\begin{array}{l}\text { Strength of the } \\
\text { initial opinion }\end{array}$ & $-0.028 * * *(0.006)$ & $-0.027 * * *(0.006)$ & $-0.026 * * *(0.007)$ \\
\hline Topic: painting & $0.029(0.024)$ & $0.006(0.028)$ & $0.064 *(0.035)$ \\
\hline Topic: migration & $0.127 * * *(0.033)$ & $0.121 * * *(0.035)$ & $0.111 * *(0.051)$ \\
\hline $\begin{array}{l}\text { Negative initial } \\
\text { diff.*migration }\end{array}$ & $-0.119 * * *(0.040)$ & $-0.102 * *(0.049)$ & $-0.122 * *(0.054)$ \\
\hline Topic: carbon tax & $0.055(0.036)$ & $0.074 * *(0.037)$ & $0.004(0.051)$ \\
\hline $\begin{array}{l}\text { Negative initial } \\
\text { diff. }{ }^{*} \text { carbon tax }\end{array}$ & $-0.076 *(0.043)$ & $-0.122 * *(0.049)$ & $0.009(0.065)$ \\
\hline Order & $0.059 *(0.034)$ & $-0.027(0.124)$ & $-0.096(0.097)$ \\
\hline Period & $0.001(0.002)$ & $-0.0001(0.003)$ & $0.004(0.003)$ \\
\hline Female & $0.050(0.041)$ & $0.278(0.042)$ & $0.080(0.056)$ \\
\hline Session dummies & yes & yes & yes \\
\hline $\mathrm{N}$ (by category) & $4044(283-1814-1947)$ & $2678(167-995-1516)$ & $1366(116-819-431)$ \\
\hline $\mathrm{Nb}$ of clusters & 234 & 234 & 120 \\
\hline Log Pseudolik. & -3167.353 & -1997.774 & -1112.616 \\
\hline Wald Chi2 & 444.40 & 404.25 & 137.89 \\
\hline Prob $>$ Chi2 & 0.000 & 0.000 & 0.000 \\
\hline Pseudo- $\mathrm{R}^{2}$ & 0.128 & 0.136 & 0.075 \\
\hline
\end{tabular}

Note: Marginal effects are reported with robust standard errors in parentheses. ${ }^{*},{ }^{* *}$, and $* * *$ indicate significance at the $10 \%, 5 \%$ and $1 \%$ level, respectively. $\mathrm{N}$ by category refers to the number of cases in which first movers increase the distance, keep the distance stable and decrease the distance, respectively. In Model (1), the reference category is the Random treatment. In all models the omitted topic is music.

Model (1) shows that the Ingratiation treatment increases the likelihood of shifting one's opinion towards the second mover by $26.81 \%$, compared to the Random treatment. The performance has no effect on this likelihood. In contrast, the probability of reducing the distance increases with the initial distance, at a decreasing rate. As predicted, it is lower when the participant reported a stronger belief in his opinion. Some topics are more likely to lead to ingratiation. The statement about the regularization of illegal immigrants increases by $12.74 \%$ the likelihood of reducing the distance in opinion. This effect is asymmetric: it vanishes when the individual holds opinions that are less conservative than that of the second mover. When opinion is about the environmental tax, the first movers who hold a more liberal opinion than 
their second mover are less likely to conform (-7.57\%). For these policy-oriented topics, ingratiation/conformism is more likely when the first mover is more conservative than the second mover. One interpretation of this asymmetry is in terms of social desirability or protective behavior. Subjects may fear that holding an opinion that is more "conservative" than that of the second mover will be negatively perceived. Another interpretation could be that more conservative people are less ideological and have a lower moral cost in changing opinion strategically. In contrast, those who hold less conservative opinions are less likely to change their opinion in the direction of greater conservatism. ${ }^{13,14}$ In Models (2) and (3), the impact of the initial distance is $2.57 \%$ for each difference point in the Ingratiation treatment and $1.19 \%$ in the Random treatment. Table 2 also indicates that the probability of increasing the distance with the second mover's opinion is marginally lower when the performance is lower (only in the Ingratiation treatment), when the initial distance is higher (but nonlinearly), and when opinions are related to policy issues in the Ingratiation treatment.

Next, we study the determinants of the ingratiation index. We estimate Tobit models with robust standard errors clustered at the first mover level. We use these censored normal regression models because the data on the dependent variable are censored both on the left at 0 (no change in opinion) and on the right at 1 (perfect ingratiation). ${ }^{15}$ Using normal Ordinary

\footnotetext{
${ }^{13}$ This effect is not due to a specific distribution of the differences in initial opinions in this topic relative to the other topics (see Figure 1A in Appendix that displays the distribution of differences in opinions for each topic). Nor is this due to a difference in the strength of opinion across topics. Two-tailed Wilcoxon tests with the subject as one independent unit of observation show that the strength of the opinion is not different between music (reference), migration $(p=0.780)$ and carbon tax $(p=0.437)$; opinions about painting are less certain $(p<0.001)$.

${ }^{14}$ Note that excluding from the independent variables the interaction terms between the topic of the statement and the direction of the opinion difference keeps these results almost unchanged. In particular, the opinion about immigration still increases significantly the probability of conforming to the second mover's opinion. See Table A2 in Appendix. Adding the negative initial difference in the opinion about painting and music to the independent variables does not modify the previous results either. The coefficient associated with a more positive opinion about music is never significant. The coefficient associated with painting is never significant but a more positive opinion than that of the second mover increases the probability of changing opinion (significant at the 5\% level in model 1 and model 2 and at the $10 \%$ level in model 3). Since the negative initial difference is not significant for all topics and since its coefficient is sometimes positive and sometimes negative, the negative difference for the polemic topic is not an artifact of the econometric analysis.

${ }^{15}$ We also estimated a two-step model to deal with a potential selection bias. Indeed, the individuals who decide to conform may have specific characteristics; explaining the index without taking into account this selection may
} 
Least Squares models on the whole sample would provide inconsistent estimates since they assume linearity. We exclude anti-conformist individuals and those who have the same initial opinion as the manager since they do not ingratiate themselves. The independent variables are the same as in Table 2. In particular, the initial difference in opinions allows us to indicate whether ingratiation is stronger or weaker when the opinions were initially more distant, while the index focuses on the reduction of the difference in relative terms. Model (1) pools the data from the Ingratiation and Random treatments; models (2) and (3) analyze each treatment separately. Table 3 reports the estimates.

Table 3. Determinants of the ingratiation index - Tobit models

\begin{tabular}{|c|c|c|c|}
\hline $\begin{array}{l}\text { Dependent variable: } \\
\text { Ingratiation index }\end{array}$ & $\begin{array}{l}\text { Ingratiation and } \\
\text { Random treatments } \\
(1)\end{array}$ & $\begin{array}{c}\text { Ingratiation } \\
\text { treatment } \\
(2) \\
\end{array}$ & $\begin{array}{l}\text { Random } \\
\text { treatment } \\
(3) \\
\end{array}$ \\
\hline Ingratiation treatment & $0.465 * * *(0.056)$ & - & (2) \\
\hline Performance & $-0.026(0.020)$ & $-0.043 *(0.020)$ & $0.007(0.042)$ \\
\hline Strength of the initial opinion & $-0.040 * * *(0.009)$ & $-0.035 * * *(0.009)$ & $-0.054 * * *(0.017)$ \\
\hline Initial opinion difference & $0.028 * * *(0.003)$ & $0.032 * * *(0.003)$ & $0.021 * * *(0.005)$ \\
\hline Squared initial difference & $-0.0002 * * *(<0.001)$ & $-0.0003 * * *(<0.001)$ & $-0.0002 * * *(<0.001)$ \\
\hline Topic: painting & $0.035(0.033)$ & $0.023(0.037)$ & $0.077(0.062)$ \\
\hline Topic: migration & $0.197 * * *(0.049)$ & $0.192 * * *(0.050)$ & $0.209 * *(0.098)$ \\
\hline Negative initial diff.*migration & $-0.218 * * *(0.066)$ & $-0.198 * * *(0.068)$ & $-0.276^{* *}(0.140)$ \\
\hline Topic: carbon tax & $0.072(0.053)$ & $0.083(0.054)$ & $0.040(0.108)$ \\
\hline Negative initial diff. ${ }^{*}$ carbon tax & $-0.087(0.069)$ & $-0.108(0.075)$ & $-0.036(0.133)$ \\
\hline Order & $0.090 *(0.053)$ & $-0.020(0.177)$ & $-0.136(0.205)$ \\
\hline Period & $0.007 *(0.003)$ & $0.006(0.004)$ & $0.011(0.008)$ \\
\hline Female & $0.066(0.066)$ & $0.018(0.067)$ & $0.191 *(0.115)$ \\
\hline Session dummies & yes & yes & yes \\
\hline Constant & $-0.470 * * *(0.170)$ & $0.046(0.155)$ & $-0.318(0.236)$ \\
\hline $\mathrm{N} /$ Left-/ right-censored obs. & $3761 / 1814$ / 364 & $2511 / 995 / 301$ & $1250 / 819 / 63$ \\
\hline $\mathrm{Nb}$ of clusters & 234 & 234 & 120 \\
\hline Log-pseudolikelihood & -3261.912 & -2291.949 & -923.942 \\
\hline $\mathrm{F} /$ Prob $>F$ & $11.43 / 0.000$ & $11.58 / 0.000$ & $3.36 / 0.000$ \\
\hline Pseudo $\mathrm{R}^{2}$ & 0.106 & 0.090 & 0.059 \\
\hline
\end{tabular}

bias the estimates. Therefore, in the first step, we estimated Probit selection models of the probability to conform or not, by treatment. Robust standard errors were clustered. We derived from these regressions the Inverse of Mill's Ratio. In the second step, we estimated OLS models in which the dependent variable is the ingratiation index, by treatment. The independent variables include the Inverse of Mill's Ratio estimated in the first step to account for the possible selection effect. Since IMR was not significant in these regressions, this indicates that there is no selection bias. Therefore, our Tobit models accounting for censored data are the appropriate models. 
The significantly higher index in the Ingratiation than in the Random treatment (model (1)) confirms the presence of strategic conformism. The index is significantly higher when the initial difference in opinions is larger; the relationship is not linear. The strength of the initial opinion reduces the size of the index in both treatments (models (2) and (3)). In both treatments, the index increases when opinions are relative to the immigration statement, at least for the first movers who hold a more conservative opinion than the second mover. ${ }^{16,17}$

Model (2) in Table 3 also shows that the ingratiation index decreases with the performance at the task in the Ingratiation treatment. When interaction terms are excluded (see Table A3), the coefficient associated with the performance variable is significant at the 5\% level. This indicates a substitution effect between ingratiation and ability: a subject who performs poorly revises his opinion to a larger extent than a good performer. This could be due to both a strategic motivation and a greater moral license to change his opinion if the individual believes that the random draw of questions has been unfavorable to him. ${ }^{18}$ The coefficient is, however, small: even a good performer may have a high ingratiation index because he does not know about others' performance.

As a robustness test, we have also estimated another index of ingratiation that measures ingratiation in proportional rather than absolute terms and that can take into account the fact that some first movers change their opinion to the opposing view of their second mover's opinion. This alternative index is calculated as: $I^{a l t}=($ final opinion - initial opinion $) /($ second mover's opinion - initial opinion). If $0<I^{a l t}<1$, then the first mover's opinion moved toward

\footnotetext{
${ }^{16}$ We estimated the same models on the restricted sample of first movers who strictly reduced the distance in opinion. The main differences are an increased level of significance of the performance in the Ingratiation treatment $(p=0.040)$ and a loss of significance of the topic variables in both treatments although the negative impact of having more liberal opinions on illegal immigration in the Ingratiation treatment is almost significant $(p=0.107)$.

${ }^{17}$ When estimating the same models without the interaction terms between the topic and the direction of the difference in opinion, the immigration question still captures a significant positive coefficient except in the Random treatment where its coefficient is no longer significant (see model (3) in Table A3 in Appendix). Including the negative initial difference in the opinion about painting and about music has the same impact. The coefficient associated with a more positive opinion about music is never significant. A more positive opinion about the painting increases the index (significant at the $5 \%$ level in model 1, at $10 \%$ in models 2 and 3 ).

${ }^{18}$ We thank an anonymous reviewer for this possible interpretation.
} 
the second mover's opinion. $I^{\text {alt }}=1$ corresponds to perfect ingratiation, and $1<I^{a l t}<2$ indicates that the first mover's opinion moved towards the opposite side of the second mover's opinion, while getting closer to it. We have estimated the same models as in Table 3 separately for the first movers with $0<I^{\text {alt }} \leq 1$ and for those with $1<I^{\text {alt }} \leq 2$, excluding from the independent variables the initial distance in opinion since this measure is directly included in the definition of the dependent variable (regressions available upon request). When $0<I^{\text {alt }} \leq 1$, the regressions deliver the same qualitative results as Table 3. When $1<I^{a l t} \leq 2$ (which represents 274 out of 2,511 observations in the Ingratiation treatment and 50 out of 1,250 in the Random treatment), the strength of the initial opinion and the performance are no longer significant. In the Ingratiation treatment, the index gets significantly closer to 1 when opinions are relative to the immigration statement (coeff. $=-0.132, p=0.009$ ). This indicates that for more controversial topics, some first movers conform not only by moving closer to the second mover but also by going beyond his opinion (a more conservative first mover will become even more liberal than his second mover).

To sum up, our analysis supports these results:

Result 1. Many individuals - but not all - change their initial opinion strategically after learning of the second mover's opinion. Consistent with hypothesis 1, opinion conformity is more likely in the Ingratiation than in the Random treatment in which non-strategic changes of opinions may be due to a pure taste for conformity, social desirability or social learning.

Result 2. Supporting hypothesis 2 , the ingratiation index is negatively correlated with a stronger initial opinion, which may be associated with a higher (unobservable) moral cost of conformity. More conservative opinions on debated issues increase ingratiation and conformity.

Result 3. Supporting hypothesis 3, there is a small substitution effect between the performance at the task and the ingratiation index. First movers with low performance tend to revise their opinion more.

We analyze now the determinants of the payoff assignment. 


\subsection{Determinants of the payoff assignment}

To measure the impact of opinion proximity and ingratiation, we first consider the rate of success of a first mover depending on his ranking in the triad, based on his performance and on opinion distance. The "performance rank" 1 (3) is assigned to the first mover who gets the highest (lowest, respectively) performance; the "opinion rank" 1 (3) is assigned to the first mover whose reported opinion is the closest (most distant) to the second mover's opinion. Ranks 2 are assigned to intermediate performances or opinions. In the Baseline, the share of best performers who receive the high payoff is $42.49 \%$ (56.68\% after exclusion of ties among the best performers); in the Ingratiation treatment, these percentages are 46.55 (proportion test comparing Ingratiation and Baseline in period $1, p=0.993)$ and $67.57(p=0.365)$. Figure 2 displays the relative frequency of first movers who get the high payoff by ranks and treatment.
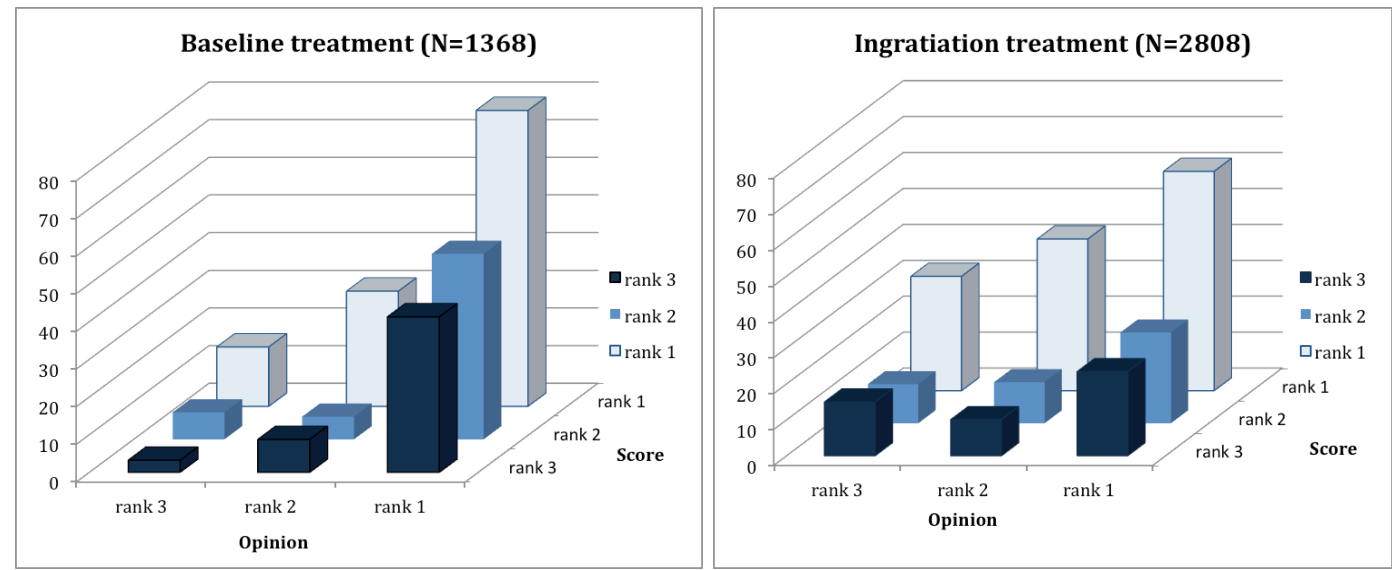

Fig. 2. Percentage of first movers receiving the high payoff by ranks and treatment

For each opinion rank, Figure 2 indicates that having the first performance rank always increases the likelihood of receiving the high payoff in the Baseline. But it also shows that for any performance rank, having the first opinion rank increases dramatically the probability of receiving the high payoff. Only the first opinion rank allows a first mover to earn more than a random assignment of payoff regardless of the performance rank, whereas having the first performance rank makes the first mover better off than a random assignment only if he also 
holds the first opinion rank. The Ingratiation treatment rebalances the influence of performances and opinions: the first opinion rank is rewarded much less than in the Baseline. Now, only the first performance rank allows a first mover to earn more than a random assignment, except when he holds the third opinion rank. Second movers put less weight on opinions when they expect brown-nosing.

$89.25 \%$ of the second movers asked information on both the first movers' performances and opinions in the Baseline; the corresponding values were $95.51 \%$ and $82.08 \%$ in the Ingratiation and the Random treatments, respectively. ${ }^{19}$ We use a Probit model with robust standard errors clustered at the second mover level to analyze the probability for the second mover of looking at both performances and opinions (dependent variable equal to 1), or not (dependent variable equal to 0$){ }^{20}$ This model shows that this probability is significantly higher in the Ingratiation treatment than in the Baseline $(p=0.020)$; it is not different in the Random treatment and the Baseline $(p=0.443)$; it is lower for males $(p=0.026)$ and older second movers $(p<0.001)$.

To study the determinants of which first mover receives the high payoff we estimate conditional Logit models with fixed effects and robust standard errors clustered at the second mover level. Indeed, conditional Logit models allow us to estimate the effects of the choice variables on the probability of choosing one particular first mover, conditional on the attributes of the choice alternatives, i.e. the characteristics of the other triad members. Fixed effect estimates use within-individual differences. The independent variables include performance and opinion ranks (Rank 2 being the reference) and dummy variables for a tie in the performance Rank 1 or in the opinion Rank 1. A variable interacts with the first ranks in both opinion and performance in case of a tie in the performance rank to test whether the

\footnotetext{
${ }^{19}$ The percentage of second movers who ask only information on performances is $5.26 \%$ in the Baseline, $1.39 \%$ in the Ingratiation treatment and $0.21 \%$ in the Random treatment. The percentages of those who ask only information on opinions are $4.82 \%, 2.78 \%$ and $5.62 \%$, respectively. $0.66 \%, 0.32 \%$ and $12.08 \%$ of second movers, respectively, do not ask information at all.

${ }^{20}$ The data are available on request.
} 
opinion rank is used to split the tie. A similar variable is built for a tie in the opinion rank. The independent variables also include the distance in opinion and a dummy variable indicating whether the first mover reports exactly the same opinion as the second mover. We also interact the distance in opinion and each topic, and dummy variables indicating a negative difference in opinion for the immigration and carbon tax statements (i.e. a less conservative opinion of the first mover compared to the second mover). Opinion topics, order, periods, session and first mover's gender variables are not directly included because there is no within-group variation. We only include the observations in which second movers looked at both performances and opinions. ${ }^{21}$ Table 4 displays the marginal effects of these variables in the Baseline (Model (1)) and the Ingratiation treatment (Model (2)). We also report regressions excluding ties among the best performers. Excluding ties leaves aside the data from the whole triad.

Table 4 shows that having the best performance in the triad increases the probability of receiving the high payoff by $31.82 \%$ in the Baseline and by $34.70 \%$ in the Ingratiation treatment. These effects decrease in the case of ties. Having the lowest performance is sanctioned, but only in the Baseline and this is borderline significant. Having the smallest opinion distance increases the chance of receiving the high payoff by $22.47 \%$ in the Baseline and by $9.67 \%$ in the Ingratiation treatment (the effects remain when we exclude ties in performance rank 1). A higher opinion distance in absolute value is punished in the Baseline (the "reported distance in opinion" variable), with an additional effect when opinions are about policy topics ("final distance*migration" and "final distance*carbon tax" variables). A first mover's less conservative opinion on migration policy than the second mover's

\footnotetext{
${ }^{21}$ To control for a possible selection bias, it could be appropriate to use a two-step procedure of estimation, with a selection equation estimated by a Probit model of the second mover's choice to look at both performances and opinions. However, it is not possible to estimate a conditional Logit in the second step because the Inverse of the Mill's Ratio (IMR) given by the selection equation does not vary within the group of three first movers. Estimating simple Logit models in the second step indicates that the IMR is not significant, showing no evidence of a selection bias in the second movers who choose to look at both performances and opinions. Therefore, it is appropriate to use the conditional Logit models which results are reported in Table 4.
} 
("negative final distance*migration" variable) is rewarded more than a more conservative opinion in the Baseline. In the Ingratiation treatment, second movers pay little attention to the absolute value of the difference in opinion since they probably anticipate that the first movers may have changed their opinion; a higher difference in opinion is sanctioned only when the statement is about the carbon tax. Finally, there is no additional effect of having the first rank in case of a tie in the other dimension.

Table 4. Determinants of which first mover receives the high payoff - Conditional fixed effects Logit models with robust standard errors clustered at the second mover level

\begin{tabular}{|c|c|c|c|c|}
\hline \multirow{2}{*}{$\begin{array}{l}\text { Dependent variable: } \\
\text { Probability of receiving } \\
\text { the high payoff }\end{array}$} & \multicolumn{2}{|c|}{ Baseline treatment (1) } & \multicolumn{2}{|c|}{ Ingratiation treatment (2) } \\
\hline & All obs. & $\begin{array}{l}\text { Excluding ties } \\
\text { in perf. rank } 1\end{array}$ & All obs. & $\begin{array}{l}\text { Excluding ties } \\
\text { in perf. rank } 1\end{array}$ \\
\hline Performance rank 1 & $\begin{array}{c}0.318 * * * \\
(0.079)\end{array}$ & $\begin{array}{l}0.338 * * * \\
(0.078)\end{array}$ & $\begin{array}{l}0.347 * * * \\
(0.033)\end{array}$ & $\begin{array}{l}0.310 * * * \\
(0.029)\end{array}$ \\
\hline Tie in performance rank 1 & $\begin{array}{c}-0.233 * * * \\
(0.086)\end{array}$ & - & $\begin{array}{l}-0.217 * * * \\
(0.076)\end{array}$ & - \\
\hline Performance rank 3 & $\begin{array}{l}-0.123^{\mathrm{a}} \\
(0.079)\end{array}$ & $\begin{array}{l}-0.171^{*} \\
(0.090)\end{array}$ & $\begin{array}{l}-0.056 \\
(0.077)\end{array}$ & $\begin{array}{l}-0.053 \\
(0.079)\end{array}$ \\
\hline $\begin{array}{l}\text { Performance rank } 1 \text { with a tie in } \\
\text { opinion rank } 1\end{array}$ & $\begin{array}{c}0.043 \\
(0.146)\end{array}$ & $\begin{array}{c}0.022 \\
(0.215)\end{array}$ & $\begin{array}{c}0.022 \\
(0.079)\end{array}$ & $\begin{array}{c}0.141 \\
(0.089)\end{array}$ \\
\hline Opinion rank 1 & $\begin{array}{c}0.225 * * * \\
(0.058)\end{array}$ & $\begin{array}{l}0.256 * * * \\
(0.072)\end{array}$ & $\begin{array}{l}0.097 * * * \\
(0.031)\end{array}$ & $\begin{array}{c}0.094 * * \\
(0.043)\end{array}$ \\
\hline Tie in opinion rank 1 & $\begin{array}{l}-0.191 * \\
(0.103)\end{array}$ & $\begin{array}{l}-0.068 \\
(0.162)\end{array}$ & $\begin{array}{l}-0.162 * \\
(0.090)\end{array}$ & $\begin{array}{l}-0.151 \\
(0.136)\end{array}$ \\
\hline Opinion rank 3 & $\begin{array}{l}-0.017 \\
(0.070)\end{array}$ & $\begin{array}{c}0.079 \\
(0.082)\end{array}$ & $\begin{array}{l}-0.021 \\
(0.039)\end{array}$ & $\begin{array}{l}-0.035 \\
(0.048)\end{array}$ \\
\hline $\begin{array}{l}\text { Opinion rank } 1 \text { with a tie in } \\
\text { performance rank } 1\end{array}$ & $\begin{array}{c}0.049 \\
(0.089)\end{array}$ & - & $\begin{array}{c}0.039 \\
(0.044)\end{array}$ & - \\
\hline $\begin{array}{l}\text { Reported distance } \\
\text { in opinion }\end{array}$ & $\begin{array}{c}-0.006 * * * \\
(0.002)\end{array}$ & $\begin{array}{l}-0.008 * \\
(0.004)\end{array}$ & $\begin{array}{l}-0.001 \\
(0.001)\end{array}$ & $\begin{array}{c}0.002 \\
(0.002)\end{array}$ \\
\hline Same opinion as the second mover & $\begin{array}{l}-0.071 \\
(0.093)\end{array}$ & $\begin{array}{l}-0.123 \\
(0.103)\end{array}$ & $\begin{array}{c}0.030 \\
(0.039)\end{array}$ & $\begin{array}{c}0.046 \\
(0.063)\end{array}$ \\
\hline Final distance $*$ painting & $\begin{array}{l}-0.004 \\
(0.004)\end{array}$ & $\begin{array}{l}-0.004 \\
(0.007)\end{array}$ & $\begin{array}{l}-0.002 \\
(0.002)\end{array}$ & $\begin{array}{l}-0.004 \\
(0.003)\end{array}$ \\
\hline Final distance $*$ migration & $\begin{array}{c}-0.006^{*} \\
(0.003)\end{array}$ & $\begin{array}{c}-0.0004 \\
(0.004)\end{array}$ & $\begin{array}{l}-0.002 \\
(0.002)\end{array}$ & $\begin{array}{l}-0.007^{\mathrm{b}} \\
(0.004)\end{array}$ \\
\hline Final distance $*$ carbon tax & $\begin{array}{l}-0.005^{*} \\
(0.003)\end{array}$ & $\begin{array}{l}-0.005 \\
(0.005)\end{array}$ & $\begin{array}{c}-0.004 * * \\
(0.002)\end{array}$ & $\begin{array}{c}-0.005^{*} \\
(0.003)\end{array}$ \\
\hline $\begin{array}{l}\text { Negative final difference* migration } \\
\text { Negative final difference* carbon tax }\end{array}$ & $\begin{array}{c}0.199 * \\
(0.105) \\
-0.017 \\
(0.156) \\
\end{array}$ & $\begin{array}{c}0.097 \\
(0.129) \\
-0.031 \\
(0.223) \\
\end{array}$ & $\begin{array}{c}-0.016 \\
(0.058) \\
0.085^{\mathrm{a}} \\
(0.053) \\
\end{array}$ & $\begin{array}{c}-0.097 \\
(0.088) \\
0.118 \\
(0.073)\end{array}$ \\
\hline $\mathrm{N} / \mathrm{Nb}$ of clusters & $1221 / 37$ & $552 / 35$ & $2682 / 77$ & $1259 / 76$ \\
\hline Log Pseudolikelihood & -277.559 & -130.114 & -803.193 & -333.401 \\
\hline Wald Chi2 & 230.32 & 100.68 & 150.74 & 113.30 \\
\hline Prob $>$ Chi2 & 0.0000 & 0.0000 & 0.0000 & 0.0000 \\
\hline Pseudo-R ${ }^{2}$ & 0.379 & 0.356 & 0.182 & 0.277 \\
\hline
\end{tabular}


Note: Marginal effects are displayed with standard errors of the marginal effects in parentheses. *, **, and *** indicate significance at the $10 \%, 5 \%$ and $1 \%$ level, respectively. ${ }^{a}$ : significant at the $12 \%$ level. ${ }^{\mathrm{b}}$ : significant at the $10.5 \%$ level.

Next, we build a tentative typology of payoff assignment functions. In order to do so, we need to estimate the value of the $\alpha$ and $\beta$ parameters for each second mover. Therefore, we estimate for each individual a conditional Logit model of the decision to assign the high payoff to a specific first mover with robust standard errors. We include all the periods in which the second mover looked at both performances and opinions. ${ }^{22}$ To retain the maximum number of observations, we pool the data from the Baseline and Ingratiation treatments. ${ }^{23}$ The value of $\alpha$ is given by the marginal effect of opinion rank 1 and the value of $\beta$ by the marginal effect of performance rank 1 . We use the combination of these parameters to situate each second mover in Figure 3. A dot on the vertical (horizontal) axis means that the second mover is influenced by the best rank in performance (opinion) while the marginal effect of the best rank in opinion (performance) is not different from 0.

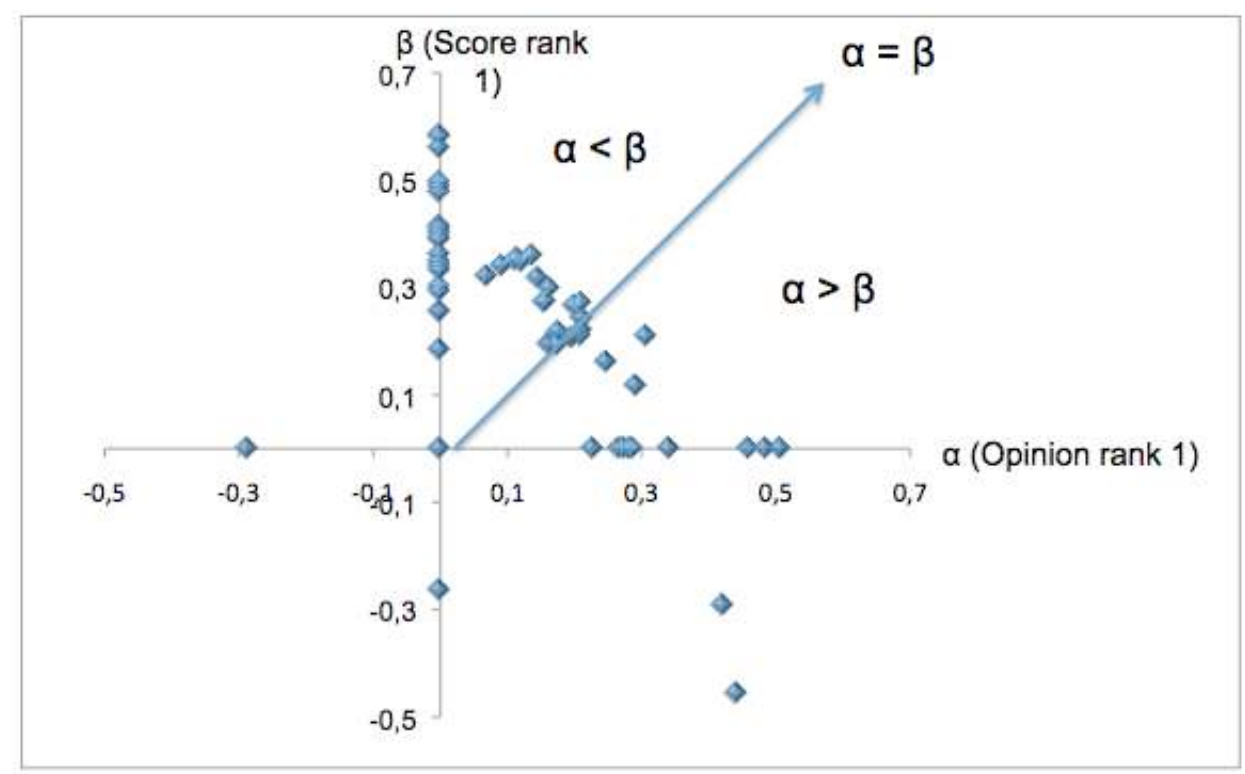

Fig. 3. Distribution of second movers' $\alpha$ and $\beta$ (marginal effects of a conditional Logit model)

The estimates allow us to identify four types with the 71 second movers for whom we reach convergence (out of 78). A first group includes 21 second movers (29.58\%) who are

\footnotetext{
${ }^{22}$ This excludes one player who looked exclusively at the opinions throughout the game.

${ }^{23}$ The minimum number of observations is 33 and the maximum 72 by subject. Pooling treatments leads to estimate an average of the coefficients for the two treatments.
} 
significantly influenced by the best performance rank but not by opinion rank; 20 of them are meritocratic second movers $(\alpha=0, \beta>0)$. A second group includes 24 second movers $(33.80 \%)$ who are influenced by both the performance and the opinion ranks $(\alpha>0, \beta>0)$. Most of them (22) are weakly meritocratic $(\beta>\alpha)$. The third group includes 11 individuals (15.49\%) who are only influenced by the best opinion rank. 10 of them are opinion-oriented second movers $(\alpha>0, \beta=0)$. A final group includes 15 indifferent second movers $(21.13 \%)$ who reward no specific dimension $(\alpha=\beta=0)$.

We summarize our results as follows:

Result 4. Only a small proportion of second movers assign payoffs randomly, although they receive no incentive to reward ability or opinion conformity. A majority of second movers are meritocratic and a large minority favor similarly-oriented first movers. This supports hypothesis 4 .

Result 5. Supporting hypothesis 5, opinion conformity is more rewarded when ingratiation is impossible. In this situation, a higher distance is more sanctioned when first movers' opinions on highly debated policy topics are more conservative.

\subsection{Policy interventions}

Three interventions introduce respectively a variation in the task that facilitates the comparison of first movers' ability, a monetary cost for changing one's opinion, and incentives for second movers. These changes exert no impact on performances (M-W tests on the first period data, $p>0.50$ ). We first test whether these changes modify ingratiatory behavior. Figure 4 and Table A4 in Appendix represent the relative frequency of changes in opinion, in the Policy treatments where subjects could change opinion.

Figure 4 shows a major change after the introduction of a monetary cost for changing opinion. The share of first movers who do not modify the opinion distance with the second mover increases from $36.82 \%$ in the initial Ingratiation treatment to $63.85 \%$ in the Ingratiation-Cost treatment (however, the difference in the first period of interaction is not significant; proportion test, $p=0.411$ ), and from $59.78 \%$ in the Random treatment to $94.59 \%$ 
in the Random-Cost treatment (first period, proportion test, $p=0.004)$. Such a cost eliminates non-strategic conformism and reduces ingratiation.

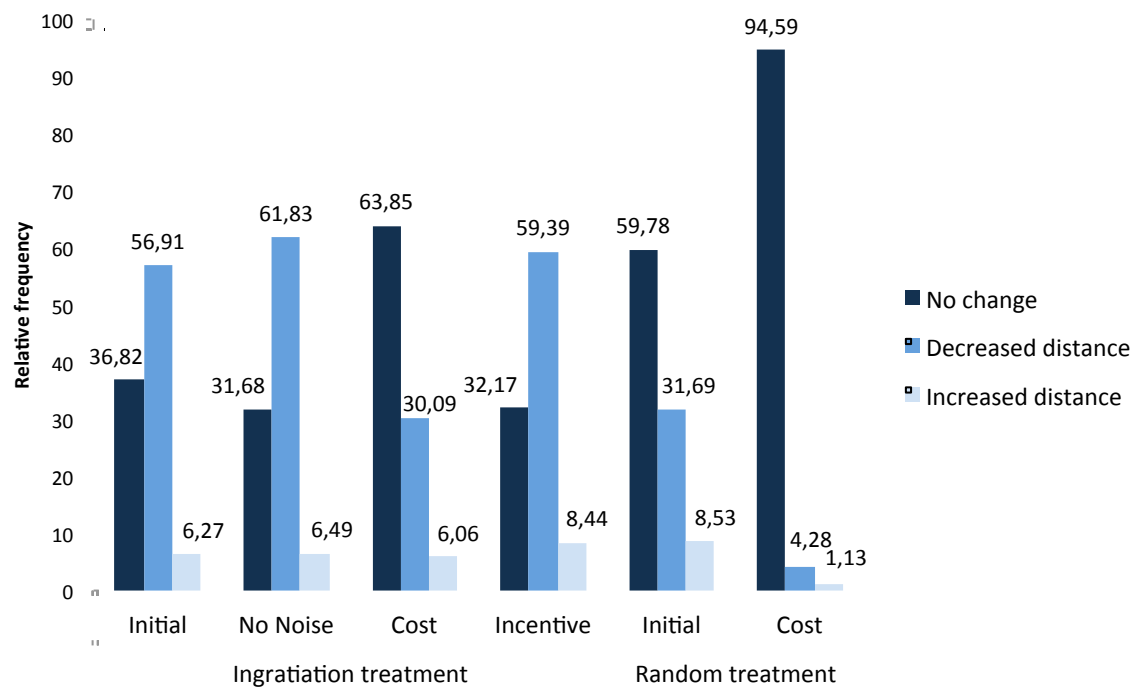

Fig. 4. Relative frequency of changes in opinion, by treatment

This is confirmed by multinomial Logit regressions in which the dependent variable is the probability of a first mover increasing, keeping constant or decreasing the distance in opinion with the second mover. ${ }^{24}$ Compared with the initial Ingratiation treatment, the introduction of a cost diminishes the probability of shortening the distance in opinion by $37.71 \%$; the other manipulations exert no significant impact. Compared with the initial Random treatment, the introduction of a cost reduces the probability of conformity by $32.79 \%$. With the initial Random treatment as the reference, the probability of ingratiation is increased by $27.08 \%$ in the initial Ingratiation treatment, $35.34 \%$ in the Ingratiation-No Noise treatment, $30.90 \%$ in the Ingratiation-Incentives treatment; there is no significant difference with the IngratiationCost treatment. The reduction of the distance remains driven by the initial distance, a lower strength of initial opinions, and an opinion related to highly debated topics. These results are also supported by Tobit estimates of the ingratiation index (see Table A6 in Appendix).

\footnotetext{
${ }^{24}$ Dummy variables for the new treatments are added to the independent variables included in the models reported in Table 2, as well as a variable interacting the performance with the No Noise treatment, since performances are measured on a larger scale in this treatment. See Table A5 in Appendix.
} 
Finally, we study whether the determinants for which first mover receives the highest payoff are affected by the new treatments. Table 5 reports the marginal effects of conditional fixed effects Logit models pooling the data from the initial and the new treatments (model (1) for the Baseline treatments and model (2) for the Ingratiation treatments), with separate regressions excluding ties in performance rank. ${ }^{25}$

Table 5. Determinants of which first mover receives the high payoff in the initial and the Policy treatments - Conditional Logit models with robust standard errors clustered at the second mover level

\begin{tabular}{|c|c|c|c|c|}
\hline \multirow{2}{*}{$\begin{array}{l}\text { Dependent variable: } \\
\text { Probability of receiving } \\
\text { the high payoff }\end{array}$} & \multicolumn{2}{|c|}{ Baseline treatments (1) } & \multicolumn{2}{|c|}{ Ingratiation treatments (2) } \\
\hline & All obs. & $\begin{array}{l}\text { Excluding ties } \\
\text { in perf. rank } 1\end{array}$ & All obs. & $\begin{array}{l}\text { Excluding ties } \\
\text { in perf. rank } 1\end{array}$ \\
\hline Performance rank 1 & $\begin{array}{c}0.328 * * * \\
(0.066)\end{array}$ & $\begin{array}{l}0.320 * * * \\
(0.080)\end{array}$ & $\begin{array}{l}0.319 * * * \\
(0.027)\end{array}$ & $\begin{array}{l}0.339 * * * \\
(0.028)\end{array}$ \\
\hline $\begin{array}{l}\text { Performance rank } 1 * \text { No } \text { Noise } \\
\text { treatment }\end{array}$ & $\begin{array}{l}0.154 \\
(0.137)\end{array}$ & $\begin{array}{c}0.074 \\
(0.133)\end{array}$ & $\begin{array}{c}0.012 \\
(0.073)\end{array}$ & $\begin{array}{c}0.013 \\
(0.084)\end{array}$ \\
\hline Performance rank $1 *$ Cost treatment & - & - & $\begin{array}{l}0.109 * * \\
(0.046)\end{array}$ & $\begin{array}{c}0.162^{* *} \\
(0.082)\end{array}$ \\
\hline Perf. rank $1 *$ Incentive treatment & $0.245^{* *}$ & $\begin{array}{c}0.474 * * * \\
(0.112)\end{array}$ & $0.180 * * *$ & $\begin{array}{c}0.251 * * * \\
(0.072)\end{array}$ \\
\hline Performance rank 3 & $(0.054)$ & $\begin{array}{l}-0.145^{*} \\
(0.079)\end{array}$ & $\begin{array}{l}0.043 \\
(0.034)\end{array}$ & $\begin{array}{l}-0.097 \\
(0.079)\end{array}$ \\
\hline $\begin{array}{l}\text { Performance } \\
\text { treatment }\end{array}$ & $\begin{array}{c}0.073 \\
(0.141) \\
-\end{array}$ & $\begin{array}{c}0.149 \\
(0.223) \\
-\end{array}$ & $\begin{array}{c}0.096 \\
(0.060) \\
-0.061 \\
(0.104)\end{array}$ & $\begin{array}{c}0.207 * * \\
(0.095) \\
0.123 \\
(0.134)\end{array}$ \\
\hline Performance rank $3 *$ Cost treatment & $\begin{array}{l}-0.185 \\
(0.120)\end{array}$ & $\begin{array}{l}-0.438 * * * \\
(0.095)\end{array}$ & $\begin{array}{l}-0.068 \\
(0.182)\end{array}$ & $\begin{array}{l}-0.198 \\
(0.299)\end{array}$ \\
\hline Perf. rank $3^{*}$ Incentive treatment & $\begin{array}{l}0.216 * * * \\
(0.031)\end{array}$ & $\begin{array}{l}0.231 * * * \\
(0.078)\end{array}$ & $\begin{array}{c}0.099 * * * \\
(0.018)\end{array}$ & $\begin{array}{l}0.099 * * * \\
(0.036)\end{array}$ \\
\hline Opinion rank 1 & $\begin{array}{c}0.033 \\
(0.102)\end{array}$ & $\begin{array}{l}-0.078 \\
(0.141)\end{array}$ & $\begin{array}{c}0.010 \\
(0.040)\end{array}$ & $\begin{array}{c}0.083 \\
(0.065)\end{array}$ \\
\hline Opinion rank $1 *$ No Noise treatment & - & - & $\begin{array}{l}-0.042 \\
(0.069)\end{array}$ & $\begin{array}{c}0.040 \\
(0.098)\end{array}$ \\
\hline Opinion rank $1 *$ Cost treatment & $\begin{array}{l}-0.008 \\
(0.077)\end{array}$ & $\begin{array}{l}-0.078 \\
(0.173)\end{array}$ & $\begin{array}{l}0.113 \\
(0.054)\end{array}$ & $\begin{array}{c}0.012 \\
(0.109)\end{array}$ \\
\hline Opinion rank $1 *$ Incentive treatment & $\begin{array}{c}0.001 \\
(0.074)\end{array}$ & $\begin{array}{c}0.064 \\
(0.089)\end{array}$ & $\begin{array}{c}0.002 \\
(0.027)\end{array}$ & $\begin{array}{l}-0.029 \\
(0.043)\end{array}$ \\
\hline Opinion rank 3 & $\begin{array}{l}-0.033 \\
(0.106)\end{array}$ & $\begin{array}{l}-0.042 \\
(0.105)\end{array}$ & $\begin{array}{c}0.071 \\
(0.051)\end{array}$ & $\begin{array}{c}-0.013 \\
(0.095)\end{array}$ \\
\hline Opinion rank $3 *$ No Noise treatment & - & - & $\begin{array}{c}0.016 \\
(0.058)\end{array}$ & $\begin{array}{c}0.098 \\
(0.079)\end{array}$ \\
\hline Opinion rank $3 *$ Cost treatment & -0.032 & -0.173 & 0.015 & -0.130 \\
\hline
\end{tabular}

\footnotetext{
${ }^{25}$ In the Baseline treatments, the share of the best performers who receive the high payoff is $42.49 \%$ in the initial treatment, $45.99 \%$ in No Noise $(p=0.933)$ and $51.56 \%$ in Incentives $(p=0.004)$; excluding ties, these values are $56.68 \%, 61.54 \%(p=0.264)$, and $77.88 \%(p=0.018)$, respectively. In the Ingratiation treatments, these proportions are $46.55 \%$ in the initial treatment, $50.18 \%$ in No Noise $(p=0.919), 49.45 \%$ in Cost and $53.83 \%$ in Incentives $(p<0.001$ for both); excluding ties, these percentages are $67.57 \%, 69.52 \%(p=0.846), 75.0 \%(p=0.005)$, and $83.62 \%(p=0.014)$, respectively. These tests are two-tailed proportion tests in the first period data.
} 


\begin{tabular}{|c|c|c|c|c|}
\hline & $(0.111)$ & $(0.132)$ & $(0.072)$ & $(0.155)$ \\
\hline Opinion rank $3 *$ Incentive treatment & $\begin{array}{c}-0.010 * * * \\
(0.003)\end{array}$ & $\begin{array}{c}-0.008 * * * \\
(0.003)\end{array}$ & $\begin{array}{c}-0.003 * * * \\
(0.001)\end{array}$ & $\begin{array}{c}-0.003 * \\
(0.002)\end{array}$ \\
\hline Distance in opinion & $\begin{array}{c}0.003 \\
(0.004)\end{array}$ & $\begin{array}{c}0.002 \\
(0.005)\end{array}$ & $\begin{array}{l}-0.004 \\
(0.003)\end{array}$ & $\begin{array}{c}0.001 \\
(0.003)\end{array}$ \\
\hline Distance $*$ No Noise treatment & - & - & $\begin{array}{c}-0.004 \\
(0.003)\end{array}$ & $\begin{array}{c}-0.007 * * \\
(0.003)\end{array}$ \\
\hline Distance $*$ Cost treatment & $\begin{array}{c}0.003 \\
(0.005)\end{array}$ & $\begin{array}{l}-0.007 \\
(0.009)\end{array}$ & $\begin{array}{l}-0.001 \\
(0.003)\end{array}$ & $\begin{array}{l}-0.003 \\
(0.003)\end{array}$ \\
\hline \multicolumn{5}{|l|}{ Distance *Incentive treatment } \\
\hline $\mathrm{N} / \mathrm{Nb}$ of clusters & $2235 / 70$ & $1050 / 66$ & $4797 / 124$ & $2273 / 122$ \\
\hline Log Pseudolikelihood & -531.908 & -230.145 & -1331.495 & -542.573 \\
\hline Wald Chi2 & 269.22 & 1282.63 & 328.97 & 298.23 \\
\hline Prob> Chi2 & 0.0000 & 0.0000 & 0.0000 & 0.0000 \\
\hline Pseudo-R ${ }^{2}$ & 0.371 & 0.402 & 0.242 & 0.348 \\
\hline
\end{tabular}

Note: Marginal effects are displayed with standard errors in parentheses. Clustering at the second mover level. $*, * *$, and $* * *$ indicate significance at the $10 \%, 5 \%$ and $1 \%$ levels respectively

Table 5 attests to the reinforced importance of holding the best performance rank for getting the high payoff in the cost and incentives conditions compared to the initial conditions. The weight of the relative performance is increased especially when incentives are introduced suggesting that reciprocity plays a role. In these treatments, second movers choose more frequently to be informed only on performances $(7.46 \%$ in the Baseline-Incentives treatment vs. $5.26 \%$ in the Baseline, proportion test, $p=0.039 ; 11.84 \%$ in the IngratiationIncentives treatment vs. $1.39 \%$ in the Ingratiation treatment, $p<0.001)$. In contrast, a reduction of noise in the measure of ability has no impact, except in a surprising direction for the less able first movers in the Ingratiation treatment (model (2), last column). Finally, Table 5 shows that the interventions do not affect significantly the importance of the best opinion rank in the assignment of payoffs compared with the initial treatments; a larger distance in opinion is still sanctioned. $^{26}$

These findings are summarized as follows:

Result 6. Introducing a monetary cost to change opinion reduces ingratiation and conformity. This supports hypothesis 2 .

\footnotetext{
${ }^{26}$ This final finding is slightly different from Bandiera et al. (2009). This could be explained by a different sequence of decisions between their study and ours. In Bandiera et al. (2009), managers can favor socially connected workers before they start working, through the allocation of workers to the tasks and through the allocation of effort among workers. In our experiment, the second mover decides the allocation of payoffs after the first mover has performed the task and reported his opinion.
} 
Result 7. Reducing the noise in the measure of performance has little effect both on first and second movers, contrary to hypothesis 6 and hypothesis 7. Introducing incentives or a cost for changing opinion increases the weight of relative ability in the assignment of payoffs. Opinion proximity remains, however, rewarded. This supports only partially hypothesis 6 .

\section{DISCUSSION AND CONCLUSION}

Our study confirms in an economically-controlled setting the evidence obtained in social psychology of the effect of ingratiation on career success, salary increases, or boardroom appointments (Gordon, 1996; Higgins et al., 2003; Westphal and Stern, 2006). It emphasizes the importance of social distance in economic behavior, as also shown by studies on cooperation (Bandiera et al., 2009) and competition (Dutcher, 2011). Many individuals in our experiment conform strategically to the opinion of the person who determines their payoff. Ingratiation is reduced when the moral or monetary cost of changing one's opinion is higher. It is more spread when opinions concern highly debated issues. This last result may seem surprising, as the moral cost of changing one's opinion is probably higher when opinion is about highly debated issues than about aesthetic-related topics because the individual has probably thought more about them. A possible explanation is that individuals fear that a difference in opinion is more likely to be sanctioned when opinion is about controversial issues. Indeed, Jones (1964) distinguishes between acquisitive ingratiation (driven by the desire to access valuable resources at a minimal cost) and protective ingratiation (motivated by the willingness to prevent a possible sanction in case of a visible disagreement). Individuals conform more to avoid being negatively perceived by the second mover. Moreover, protective ingratiation may be easier to justify in one ones' eyes than acquisitive ingratiation that may alter self-image. This probably mitigates the moral cost of ingratiation.

Ingratiation does not disappear over time as it increases expected payoffs, although opinion proximity is less rewarded when performance-pay is introduced. In this case, reciprocity could motivate second movers to reward ability more when assigning payoffs. 
This behavior may be due to various motives. Value homophily (Lazarsfeld and Merton, 1954) is the most immediate candidate as an explanation, as similarity in values has been shown to increase interpersonal attraction (Byrne et al., 1966; Liden and Mitchell, 1988). Individuals who share knowledge and tastes are also more likely to interact, notably because of ease of communication (Carley, 1991; McPherson et al., 2001). Here, groups are formed exogenously and they do not have to coordinate in a joint activity, but homophily could explain that individuals reward those who think similarly. This interpretation is supported by the fact that opinion proximity is less rewarded when second movers suspect brown-nosing and less sincere opinions. Another possible interpretation is that rewarding opinion proximity offers an alternative solution to random selection when several first movers achieve a similar performance (or to discrimination as a tie-breaking rule, see Filippin and Guala, 2013, and de Haan et al., 2011). The first explanation is more likely in our experiment, however, since opinion proximity is rewarded even in the absence of ties in performance.

Naturally, some aspects of our design can be discussed. First, we forced second movers to assign unequal payoffs. Letting second movers decide freely on how to share the total payoff between the first movers would allow us to test whether ingratiation is a specific property of tournament settings. Second, we have considered a working environment without incentives for the second mover. Introducing a principal-agent framework would allow us to study whether explicit incentives to promote the most able first mover eliminate ingratiation. Third, using a quiz gives a measure of first movers' ability but does not provide information about their willingness to exert effort. We also acknowledge that the role of luck in the difficulty of the task was important, which may increase ingratiation. A possible extension would be to consider a task in which luck does not play any role and in which performance depends either on effort or on the pure ability to identify how this would impact ingratiation. This would render the experimental setting more like a real organizational setting. The setting 
could lead to more or as much ingratiation as in the current design, because a subject can never be sure that he is the best performer and he could substitute ingratiation for painful effort. Alternatively, it could reduce ingratiation if luck can no longer be taken as an excuse for brown-nosing or if performance is expected to be rewarded more than opinion proximity when the task is more demanding. Fourth, interactions were one-shot in our design. Introducing repeated interactions and feedback, in which first mover is rewarded, would enable assessing the longer term impact of ingratiation. This impact could be negative on the abler first movers who are passed over by less productive first movers. It could be positive on favored first movers who may want to justify their better treatment. Finally, making changes in opinions visible to others would vary the moral cost of ingratiation. Making them visible to the second mover might also influence her subsequent decisions, especially if they imply a trusting relationship.

While we must be cautious about their external validity, our results may have potential implications for organizations since they show that both ingratiation and favoritism of opinion conformity are frequent and that some policy interventions can be relatively effective. Indeed, firms may try to fight against ingratiation and favoritism if they generate inefficiencies. Subjective evaluation may discourage employees to report their true opinions to their manager and encourage them to spend more effort in ingratiatory activities and less effort in productive activities that impact the profit of the firm. More generally, ingratiation may reduce the accuracy of information, which may have a detrimental effect on the quality of projects. Our experiment indicates that reducing the noise in the measure of performance (making evaluations less subjective) cannot reduce ingratiation and favoritism. It suggests that it is more effective to make ingratiation more costly in moral and economic terms (by making it more visible, for example) and to strengthen the link between managers' compensation and employees' performance. The theory of yes-men by Prendergast (1993) 
concluded that when the desire to conform is large, using incentive contracts encourages individuals to be dishonest when reporting their information. Our study sheds another light on this question and suggests that incentive contracts can reduce both the temptation of managers to reward conformity instead of performance, and employees' ingratiatory behavior.

\section{REFERENCE LIST}

Akerlof, G.A. (1980). A Theory of Social Custom, of Which Unemployment May Be One Consequence. The Quarterly Journal of Economics, 94, 749-775.

Akerlof, G.A. (1997). Social Distance and Social Decisions. Econometrica, 65, 1005-1027.

Appelbaum, S.H., Hughes, B. (1998). Ingratiation as a Political Tactic: Effects within the Organization. Management Decision, 36(2), 85-95.

Asch, S. (1951). Effects of Group Pressure upon the Modification and Distortion of Judgments. In Guetzkow, H. (Ed.), Groups, Leadership and Men Research in Human Relations. Pittsburgh: Carnegie Press, 177-190.

Bandiera, O., Barankai, I., Rasul, I. (2009). Social Connections and Incentives in the Workplace: Evidence from Personnel Data. Econometrica, 77(4), 1047-1094.

Banerjee, A.V. (1992). A Simple Model of Herd Behavior. Quarterly Journal of Economics, 107, 797-819.

Bernheim, B.D. (1994). A Theory of Conformity. Journal of Political Economy, 102(5), 841877.

Berns, G. (2008). Iconoclast: A Neuroscientist Reveals How to Think Differently. Harvard: Harvard Business Press.

Bikhchandani, S., Hirshleifer, D., Welch, I. (1992). A Theory of Fads, Fashion, Custom, and Cultural Change as Informational Cascades. Journal of Political Economy, 100, 992-1026.

Bramoullé, Y., Goyal, S. (2011). Favoritism. Mimeo, Université Laval and University of Cambridge.

Brandts, J., Sola, C. (2010). Personal Relations and their Effect on Behavior in an Organizational Setting: An experimental study. Journal of Economic Behavior and Organization, 73, 246-253.

Byrne, D., Clore, G., Worchel, P. (1966). The Effect of Economic Similarity-dissimilarity on Interpersonal Attraction. Journal of Personality and Social Psychology, 4, 220-224.

Carley, KM. (1991). A theory of group stability. American Sociological Review, 56, 331-354.

Cialdini, R.B., Goldstein, N.J. (2004). Social Influence: Compliance and Conformity. Annual Review of Psychology, 55, 591-621.

Dutcher, E.G. (2011). How Does the Social Distance Between an Employee and a Manager Affect Employee Competition for a Reward? University of Innsbrück, mimeo.

Efferson, C., Lalive, R., Fehr, E. (2008). The Coevolution of Cultural Groups and Ingroup Favoritism. Science, 321, 26 September.

Falk, A., Zehnder, C. (2013). A City-Wide Experiment on Trust Discrimination. Journal of Public Economics, 100, 15-27. 
Fershtman, C., Gneezy, U. (2001). Discrimination in a Segmented Society: An Experimental Approach. Quarterly Journal of Economics, 116(1), 351-377.

Filippin, A., Guala, F. (2013). Costless Discrimination and Unequal Achievements in a Labour Market Tournament. Experimental Economics, 16(3), 285-305.

Gardner, J. (2011). Executive Masters in Leadership - Capstone Project. Georgetown University, McDonough School of Business.

Garicano, L., Palacios, I., Prendergast, C. (2005). Favoritism Under Social Pressure. Review of Economics and Statistics, 87, 208-216.

Goldin, C., Rouse, C. (2000). Orchestrating Impartiality: The Impact of "Blind" Auditions on Female Musicians. American Economic Review, 94(4), 715-741.

Gordon, R.A. (1996). Impact of Ingratiation on Judgments and Evaluation: A Meta-analytic Investigation. Journal of Personality and Social Psychology, 71, 54-68.

Grabisch, M., Rusinowska, A. (2009). Measuring Influence in Command Games. Social Choice and Welfare, 33, 177-209.

Grabisch, M., Rusinowska, A. (2010). A Model of Influence in a Social Network. Theory and Decision, 69(1), 69-96.

Greiner, B. (2004). An Online Recruitment System for Economic Experiments. In Forschung und wissenschaftliches Rechnen GWDG Bericht 63, Ed. K. Kremer, and V. Macho. Göttingen: Gesellschaft für Wissenschaftliche Datenverarbeitung.

de Haan, T., Offerman, T., Sloof, R. (2011). Discrimination in the Labor Market: The Curse of Competition between Workers. Timbergen Institute Discussion Paper 2011-174/1.

Hargreaves Heap, S., Zizzo, D.J. (2009). The Value of Groups. American Economic Review, 99, 295-323.

Higgins, C.A., Judge, T.A., Ferris, G.R. (2003). Influence Tactics and Work Outcomes: A Meta-analysis. Journal of Organizational Behavior, 24, 89-106.

Jones, E.E. (1964). Ingratiation. New-York: Appleton-Century-Crofts.

Jones, S.R.G. (1984). The Economics of Conformism. Oxford: Blackwell.

Katz, M.L., Shapiro, C. (1986). Technology Adoption in the Presence of Network Externalities. Journal of Political Economy, 94, 822-841.

Knowles, J., Persico, N., Todd, P. (2001). Racial Bias in Motor Vehicle Searches: Theory and Evidence. Journal of Political Economy, 109(1), 203-229.

Kocher, M., Sutter, M. (2004). Favoritism of Agents - The Case of Referees' Home Bias. Journal of Economic Psychology, 25, 461-469.

Konow, J. (2009). Is fairness in the eye of the beholder? An impartial spectator analysis of justice. Social Choice and Welfare, 33(1), 101-127.

Klucharev, V., Hytönen, K., Rijpkema, M., Smids, A., Fernandez, G. (2009). Reinforcement Learning Signal Predicts Social Conformity. Neuron, 61, 140-151.

Laband, D.N., Piette, M.J. (1994). Favoritism versus Search for Good Papers: Empirical Evidence Regarding the Behavior of Journal Editors. Journal of Political Economy, 102(1), 194-203.

Lazarsfeld, P.F., Merton, R.K. (1954). Friendship as a Social Process: A Substantive and Methodological Analysis. In M. Berger, T. Abel, and C. Page (Eds.), Freedom and Control in Modern Society. New York: Van Nostrand, 18-66.

Liden, R.C., Mitchell, T.R. (1988). Ingratiatory Behaviors in Organizational Settings. Academy of Management Review, 13, 572-587. 
Manski, C.F. (1993). Identification of Endogenous Social Effects: The Reflection Problem. Review of Economic Studies, 60(3), 531-542.

McPherson, M., Smith-Lovin, L., Cook, J.M. (2001). Birds of a feather: Homophily in social networks. Annual Review of Sociology, 27, 415-444.

Milgrom, P.R. (1988). Employment Contracts, Influence Activities, and Efficient Organization Design. Journal of Political Economy, 96, 42-60.

Milgrom, P.R., Roberts, D.J. (1988). An Economic Approach to Influence Activities in Organizations. American Journal of Sociology, 94, S154-S179.

Prendergast, C. (1993). A Theory of "Yes Men". American Economic Review, 83(4), 757770.

Prendergast, C., Topel, R.H. (1996). Favoritism in Organizations. Journal of Political Economy, 104(5), 958-978.

Scharfstein, D., Stein, J. (1990). Herd Behavior and Investment. American Economic Review, $80,465-479$.

Tirole, J. (1986). Hierarchies and Bureaucraties: On the Role of Collusion in Organizations. Journal of Law, Economics, and Organizations, 2, 181-214.

Vaughan, G.M., Hogg, H.A. (2008). Introduction to Social Psychology (5th ed.). French Forest NSW, Australia: Pearson Education.

Westphal, J.D., Stern, I. (2006). The Other Pathway to the Boardroom: Interpersonal Influence Behavior as a Substitute for Elite Credentials and Majority Status in Obtaining Board Appointments. Administrative Science Quarterly, 51, 169-204.

Wortman, C.B., Linsenmeier, J.A.W. (1977). Interpersonal Attraction and Techniques of Ingratiation in Organizational Settings. In Staw, B.W., and Salancik, G.R. (Eds.), New Directions in Organizational Behavior. St Clair, Chicago, 133-178.

Zizzo, D.J. (2011). You Are not in My Boat: Common Fate and Discrimination Against Outgroup Members. International Review of Economics, 58, 91-103. 


\section{APPENDIX 1 - Instructions for the Ingratiation - Random treatments (Translated from original in}

French. The instructions for the other treatments and sessions are available upon request to the authors)

We thank you for participating in this experiment on economic decision-making. During this experiment you can earn a certain amount of money. All the transactions and payoffs are expressed in points. Your gains in points in all the periods of all parts will be added up and converted into Euros according to the following rate:

18 points $=€ 1$ or 1 point $=€ 0.0556$

In addition to the earnings you will make during the experiment, you will receive a $€ 4$ show-up fee. Your payoffs will be paid to you in cash and in private at the end of the session. All your decisions during the session will remain anonymous. You will never have to enter your name in the computer.

The experiment consists of three parts. These instructions are related to the first part of the experiment. The instructions relative to the other parts will be distributed after the first part will have been completed.

\section{Part 1}

During this part, you will have to answer four questions. Your answers to these questions will be called your "preferences". These four questions will be displayed in a random order.

\section{Question on painting}

A painting will be displayed on your computer screen during a minimum of 20 seconds and a maximum of two minutes. After watching this painting, you will have to indicate how you liked it on a graduated scale from 1 («I hate it») to 100 («I adore it »).

\section{Question on music}

You will listen to a piece of music during a minimum of 20 seconds and a maximum of two minutes. After listening, you will have to indicate how you liked it on a graduated scale from 1 («I hate it») to 100 («I adore it »).

\section{Questions on policy issues}

You will have to express your opinion on two policy issues. You express your opinion on a graduated scale from 1 (« extremely unfavorable») to 100 (« extremely favorable »).

We ask you to answer these questions with sincerity. Your answers will be used in the second part of the experiment. We remind you that all your answers in this experiment will remain anonymous. When you have answered these questions on your preferences, you will have to answer to a series of complementary questions. Your answers to these questions will not be used in the remaining of the experiment.

It is strictly forbidden to communicate with the other participants throughout the experiment. Any attempt to communicate may lead to the exclusion from the session without any compensation.If you have any question related to the first part of the experiment, please raise your hand. We will answer your questions in private.

\section{Part 2 (distributed after part 1 was completed)}

This part consists of 12 periods and involves two roles. During this part, you are either a participant A, or a participant B. This role is assigned randomly. It is displayed on your computer screen. You keep the same role throughout this part.

In each period, we form groups of four participants. Each group consists of one participant A and three participants B. The composition of groups is rematched randomly at the beginning of each period. In each group, the role of participants B is to perform a task. Then, the role of participant A is to decide on the assignment of two possible payoffs to participants B.

\section{$\circ$ Description of each period}

One period consists of four stages.

In the first stage, the preference of the participant A expressed in response to one of the four questions in the first part (the preference regarding either the painting, the piece of music, or one of the two social issues) is displayed on the computer screen of his group members.

In the second stage, each participant B has to perform a task. This task consists of answering two questions randomly drawn from a general knowledge quiz including a hundred items. The questions may differ across participants. A few examples are displayed in the Table below. 
What is the oldest auction house in the world? Christie's / Sotheby's / Bonhams

Which tennis tournament does not belong to the grand slam? The US Open / the Monte Carlo Masters Series / the Wimbledon tournament

What is the capital of Italy? Paris / Londres / Rome

The number of correct answers $(0,1$ or 2$)$ determines the participant B's « score » for the current period. Each participant B is informed of his own score.

In the third stage, each participant B is reminded on his computer screen of the preference he has expressed in part 1 in response to the question selected in the first stage. He can change this preference before it is communicated to the participant A.

In the fourth stage, the participant A must decide which of the three participants B will receive a payoff of 10 points for the period. The two other participants will receive a payoff of 5 points. If he wishes, before making his decision, the participant A can be informed on the scores of the three participants B (their number of correct answers in the quiz) and/or on the preferences they have expressed in stage 3 regarding the question selected in stage 1 of this period.

In each group:

- How are payoffs calculated in each period?

- The participant A earns 12 points.

- The participant B selected by the participant A earns 10 points.

- The two other participants B earn 5 points each.

\section{What does change from one period to the next?}

At the beginning of each period, the groups of four participants are rematched randomly. There are always one participant A and three participants B in each group. Each participant keeps the same role (participant A or participant B) in all the periods in this part.The reference question (relative to the painting, the piece of music or the two social issues) may change in each period.

Please read again these instructions. If you have any question, please raise your hand. We will answer your questions in private.

\section{Part 3 (distributed after part 2 was completed)}

The instructions for the third part of the experiment are similar to the instructions for part 2, except regarding the fourth stage. Now, the participant $B$ who receives the payoff of 10 points is selected randomly.

To summarize:

- The third part consists of 12 periods.

- You keep the same role as in the second part.

- The groups are rematched randomly in each period.

- In each period, one of the four questions of the first part, relative to the painting, the piece of music or one of the social issues, is selected.

- The participant A's preference regarding the selected question is displayed on the computer screen of all the group members.

- The participants B perform a task. It consists of answering to two questions extracted from a general knowledge quiz and that differ across participants B. The numbers of their correct answers constitute the scores of participants B.

- The participants B can change the preference they have expressed in part 1 relative to the question selected in stage 1 of the current period.

- A random draw determines which of the three participants B will receive the payoff of 10 points in the current period. The two other participants B will receive the payoff of 5 points. If he wishes, before the random draw, the participant A can be informed on the scores of the three participants B (their number of correct answers in the quiz) and/or on the preferences they have expressed in stage 3 regarding the question selected in stage 1 of this period.

Please read again these instructions. If you have any question, please raise your hand. We will answer your questions in private. After the 12 periods have been completed, we will ask you to answer a few demographic questions. Please remain seated until we invite you to leave the laboratory. 
APPENDIX 2. TABLES

Table A1. Characteristics of the experimental sessions

\begin{tabular}{ccl}
\hline $\begin{array}{c}\text { Session } \\
\text { number }\end{array}$ & $\begin{array}{c}\text { Number of } \\
\text { participants }\end{array}$ & \multicolumn{1}{c}{ Treatments/order } \\
\hline 1 & 20 & Ingratiation-Baseline \\
2 & 20 & Ingratiation-Baseline \\
3 & 20 & Ingratiation-Baseline \\
4 & 20 & Baseline-Ingratiation \\
5 & 20 & Baseline-Ingratiation \\
6 & 16 & Baseline-Ingratiation \\
7 & 16 & Ingratiation-Baseline \\
8 & 20 & Baseline-Ingratiation \\
9 & 20 & Ingratiation-Random \\
10 & 20 & Random-Ingratiation \\
11 & 16 & Random-Ingratiation \\
12 & 12 & Ingratiation-Random \\
13 & 20 & Ingratiation-Random \\
14 & 16 & Ingratiation-Random \\
15 & 20 & Ingratiation-Random \\
16 & 16 & Random-Ingratiation \\
17 & 20 & Random-Ingratiation \\
18 & 12 & Ingratiation-Baseline - No Noise \\
19 & 16 & Ingratiation-Baseline - No Noise \\
20 & 20 & Baseline-Ingratiation - No Noise \\
21 & 12 & Baseline-Ingratiation - No Noise \\
22 & 16 & Ingratiation-Random - Cost \\
23 & 16 & Ingratiation-Random - Cost \\
24 & 20 & Ingratiation-Random - Cost \\
25 & 12 & Ingratiation-Baseline - Incentives \\
26 & 20 & Ingratiation-Baseline - Incentives \\
27 & 16 & Ingratiation-Baseline - Incentives \\
28 & 12 & Baseline-Ingratiation - Incentives \\
29 & 16 & Baseline-Ingratiation - Incentives \\
\hline TOTAL & 500 & \\
\hline
\end{tabular}


Table A2. Determinants of the probability of decreasing the distance in opinion without interaction terms - Multinomial Logit models with robust standard errors clustered at the first mover level

\begin{tabular}{|c|c|c|c|}
\hline $\begin{array}{l}\text { Ref. = no change in } \\
\text { distance }\end{array}$ & $\begin{array}{c}\text { Ingratiation and } \\
\text { Random treatments }(1)\end{array}$ & $\begin{array}{l}\text { Ingratiation } \\
\text { treatment } \\
(2)\end{array}$ & $\begin{array}{l}\text { Random treatment } \\
\text { (3) }\end{array}$ \\
\hline Ingratiation treatment & $0.267 * * *(0.030)$ & - & - \\
\hline Performance & $0.006(0.013)$ & $<0.001(0.015)$ & $0.006(0.020)$ \\
\hline $\begin{array}{l}\text { Initial opinion } \\
\text { difference }\end{array}$ & $0.022 * * *(0.002)$ & $0.026 * * *(0.002)$ & $0.012 * * *(0.003)$ \\
\hline $\begin{array}{l}\text { Squared initial opinion } \\
\text { differ. }\end{array}$ & $-0.0002 * * *(<0.001)$ & $-0.0002 * * *(<0.001)$ & $-0.0001 * * *(<0.001)$ \\
\hline $\begin{array}{l}\text { Strength of the } \\
\text { initial opinion }\end{array}$ & $-0.028 * * *(0.006)$ & $-0.029 * * *(0.006)$ & $-0.024 * * *(0.007)$ \\
\hline Topic: painting & $0.029(0.024)$ & $0.004(0.028)$ & $0.067 *(0.035)$ \\
\hline Topic: migration & $0.063 * * *(0.024)$ & $0.070 * * *(0.027)$ & $0.035(0.037)$ \\
\hline Topic: carbon tax & $0.018(0.027)$ & $0.019(0.029)$ & $0.009(0.037)$ \\
\hline Order & $0.061 *(0.034)$ & $-0.027(0.123)$ & $-0.096(0.097)$ \\
\hline Period & $0.001(0.002)$ & $<-0.001(0.003)$ & $0.004(0.003)$ \\
\hline Female & $0.052(0.041)$ & $0.032(0.042)$ & $0.080(0.056)$ \\
\hline Session dummies & yes & yes & yes \\
\hline $\mathrm{N}$ (by category) & 4044 (283-1814-1947) & $2678(167-995-1516)$ & $1366(116-819-431)$ \\
\hline $\mathrm{Nb}$ of clusters & 234 & 234 & 120 \\
\hline Log Pseudolik. & -3175.780 & -2005.891 & -1117.721 \\
\hline Wald Chi2 & 424.49 & 397.45 & 123.95 \\
\hline Prob $>$ Chi 2 & 0.000 & 0.000 & 0.000 \\
\hline Pseudo- $\mathrm{R}^{2}$ & 0.125 & 0.132 & 0.070 \\
\hline
\end{tabular}

Table A3. Determinants of the ingratiation index without interaction terms - Tobit models

\begin{tabular}{lccc}
\hline $\begin{array}{l}\text { Dependent variable: } \\
\text { Ingratiation index }\end{array}$ & $\begin{array}{c}\text { Ingratiation and } \\
\text { Random treatments } \\
(1)\end{array}$ & $\begin{array}{c}\text { Ingratiation } \\
\text { treatment } \\
(2)\end{array}$ & $\begin{array}{c}\text { Random } \\
\text { treatment } \\
(3)\end{array}$ \\
\hline Ingratiation treatment & $0.464^{* * *}(0.056)$ & - & - \\
Performance & $-0.028(0.020)$ & $-0.045^{* *}(0.021)$ & $0.005(0.042)$ \\
Strength of the initial opinion & $-0.039^{* * *}(0.009)$ & $-0.036^{* * *}(0.009)$ & $-0.051^{* * *}(0.016)$ \\
Initial opinion difference & $0.029^{* * *}(0.003)$ & $0.032^{* * *}(0.003)$ & $0.022^{* * *(0.005)}$ \\
Squared initial difference & $-0.0002^{* * *}(<0.001)$ & $-0.0003^{* * *}(<0.001)$ & $-0.0002^{* * *}(<0.001)$ \\
Topic: painting & $0.035(0.033)$ & $0.022(0.037)$ & $0.084(0.062)$ \\
Topic: migration & $0.083^{* *}(0.036)$ & $0.088^{* *}(0.037)$ & $0.066(0.077)$ \\
Topic: carbon tax & $0.033(0.040)$ & $0.035(0.040)$ & $0.025(0.079)$ \\
Order & $0.093^{*}(0.053)$ & $-0.026(0.178)$ & $-0.125(0.207)$ \\
Period & $0.007 *(0.003)$ & $0.005(0.004)$ & $0.012(0.008)$ \\
Female & $0.069(0.067)$ & $0.020(0.068)$ & $0.195 *(0.116)$ \\
Session dummies & $y e s$ & $y e s$ & $y e s$ \\
Constant & $-0.479^{* * *}(0.171)$ & $0.054(0.154)$ & $-0.361(0.236)$ \\
\hline $\mathrm{N} /$ Left-/ right-censored obs. & $3761 / 1814 / 364$ & $2511 / 995 / 301$ & $1250 / 819 / 63$ \\
Nb of clusters & 234 & 234 & 120 \\
Log-pseudolikelihood & -3272.933 & -2299.323 & -927.025 \\
F / Prob>F & $11.89 / 0.000$ & $12.06 / 0.000$ & $3.53 / 0.000$ \\
Pseudo R & 0.103 & 0.087 & 0.056 \\
\hline
\end{tabular}


Note: Robust standard errors clustered at the first mover level are in parentheses. *, **, and *** indicate significance at the $10 \%, 5 \%$ and $1 \%$ level, respectively. In Model (1), the reference category is the Random treatment. In all models the omitted topic is music.

Table A4. Summary statistics relative to the Policy treatments allowing subjects to change opinions

\begin{tabular}{|c|c|c|c|c|}
\hline \multirow[t]{2}{*}{ Policy treatments } & \multicolumn{3}{|c|}{ Ingratiation } & \multirow{2}{*}{$\begin{array}{c}\text { Random } \\
\text { Cost }\end{array}$} \\
\hline & No Noise & Cost & Incentives & \\
\hline $\begin{array}{l}\text { Same initial opinion as the } \\
\text { second mover }\end{array}$ & $\begin{array}{c}16 \\
(2.96 \%)\end{array}$ & $\begin{array}{c}6 \\
(1.28 \%)\end{array}$ & $\begin{array}{c}56 \\
(8.19 \%)\end{array}$ & $\begin{array}{c}24 \\
(5.13 \%)\end{array}$ \\
\hline Different initial opinion & $\begin{array}{c}524 \\
(97.04 \%)\end{array}$ & $\begin{array}{c}462 \\
(98.72 \%)\end{array}$ & $\begin{array}{c}628 \\
(91.81 \%)\end{array}$ & $\begin{array}{c}444 \\
(94.87 \%)\end{array}$ \\
\hline Total number of observations & $\begin{array}{c}540 \\
(100 \%)\end{array}$ & $\begin{array}{c}468 \\
(100 \%)\end{array}$ & $\begin{array}{c}684 \\
(100 \%)\end{array}$ & $\begin{array}{c}468 \\
(100 \%)\end{array}$ \\
\hline \multicolumn{5}{|c|}{ Sub-sample of observations with a different initial opinion } \\
\hline \multicolumn{5}{|l|}{$\begin{array}{l}\text { Change between final and } \\
\text { initial distance }\end{array}$} \\
\hline - Increased distance & $\begin{array}{c}34 \\
(6.49 \%)\end{array}$ & $\begin{array}{c}28 \\
(6.06 \%)\end{array}$ & $\begin{array}{c}53 \\
(8.44 \%)\end{array}$ & $\begin{array}{c}5 \\
(1.13 \%)\end{array}$ \\
\hline - Same distance & $\begin{array}{c}166 \\
(31.68 \%)\end{array}$ & $\begin{array}{c}295 \\
(63.85 \%)\end{array}$ & $\begin{array}{c}202 \\
(32.17 \%)\end{array}$ & $\begin{array}{c}420 \\
(94.59 \%)\end{array}$ \\
\hline - Decreased distance & $\begin{array}{c}324 \\
(61.83 \%)\end{array}$ & $\begin{array}{c}139 \\
(30.09 \%)\end{array}$ & $\begin{array}{c}373 \\
(59.39 \%)\end{array}$ & $\begin{array}{c}19 \\
(4.28 \%)\end{array}$ \\
\hline Total & $\begin{array}{c}524 \\
(100 \%)\end{array}$ & $\begin{array}{c}462 \\
(100 \%)\end{array}$ & $\begin{array}{c}628 \\
(100 \%)\end{array}$ & $\begin{array}{c}444 \\
(100 \%)\end{array}$ \\
\hline $\begin{array}{l}\text { Perfect ingratiation (same final } \\
\text { opinion) }\end{array}$ & $\begin{array}{c}40 \\
(7.63 \%)\end{array}$ & $\begin{array}{c}45 \\
(9.74 \%)\end{array}$ & $\begin{array}{c}78 \\
(12.42 \%)\end{array}$ & $\begin{array}{c}8 \\
(1.80 \%)\end{array}$ \\
\hline $\begin{array}{l}\text { Almost perfect ingratiation } \\
(\text { same }+/-2)\end{array}$ & $\begin{array}{c}76 \\
(14.50 \%)\end{array}$ & $\begin{array}{c}57 \\
(12.34 \%)\end{array}$ & $\begin{array}{c}122 \\
(19.43 \%)\end{array}$ & $\begin{array}{c}11 \\
(2.48 \%)\end{array}$ \\
\hline Mean ingratiation index & $0.45(0.38)$ & $0.26(0.40)$ & $0.44(0.39)$ & $0.03(0.17)$ \\
\hline
\end{tabular}


Table A5. Determinants of the probability to change opinion distance in Policy treatments Multinomial Logit models with robust standard errors clustered at the first mover level

\begin{tabular}{|c|c|c|c|}
\hline $\begin{array}{l}\text { Ref. = no change } \\
\text { in distance }\end{array}$ & $\begin{array}{c}\text { Ingratiation and } \\
\text { Random treatments (1) }\end{array}$ & $\begin{array}{l}\text { Ingratiation } \\
\text { treatment } \\
(2) \\
\end{array}$ & $\begin{array}{l}\text { Random treatment } \\
\text { (3) }\end{array}$ \\
\hline Ingratiation treatment & $0.271 * * *(0.031)$ & - & \\
\hline Ingratiation No Noise & $0.353 * * *(0.099)$ & $0.098(0.163)$ & - \\
\hline Ingratiation Cost & $-0.154(0.097)$ & $-0.377 * * *(0.075)$ & - \\
\hline Ingratiation Incentives & $0.309^{* * *}(0.120)$ & $0.081(0.111)$ & \\
\hline Random Cost & $-0.443 * * *(0.035)$ & - & $-0.328 * * *(0.045)$ \\
\hline Performance & $0.001(0.011)$ & $-0.003(0.013)$ & $0.003(0.013)$ \\
\hline Perf. in Ingrat. No Noise & $0.014(0.028)$ & $0.019(0.029)$ & - \\
\hline Initial opinion difference & $0.022 * * *(0.002)$ & $0.028 * * *(0.002)$ & $0.010 * * *(0.002)$ \\
\hline Squared initial difference & $-0.0002 * * *(<0.0001)$ & $-0.0003 * * *(<0.0001)$ & $-0.0001 * * *(<0.0001)$ \\
\hline $\begin{array}{l}\text { Strength of the } \\
\text { initial opinion }\end{array}$ & $-0.023 * * *(0.005)$ & $-0.021 * * *(0.005)$ & $-0.017 * * *(0.005)$ \\
\hline Topic: painting & $0.011(0.019)$ & $-0.006(0.022)$ & $0.040 *(0.024)$ \\
\hline Topic: migration & $0.112 * * *(0.028)$ & $0.091 * * *(0.029)$ & $0.067 *(0.035)$ \\
\hline $\begin{array}{l}\text { Negative } \\
\text { initial diff.*migration }\end{array}$ & $-0.082 * *(0.035)$ & $-0.046(0.040)$ & $-0.055(0.036)$ \\
\hline Topic: carbon tax & $0.036(0.028)$ & $0.042(0.029)$ & $0.002(0.035)$ \\
\hline $\begin{array}{l}\text { Negative } \\
\text { initial diff.*carbon tax }\end{array}$ & $-0.064 *(0.035)$ & $-0.079 * *(0.039)$ & $0.004(0.044)$ \\
\hline Order & $0.056 *(0.033)$ & $0.080(0.143)$ & $-0.055(0.066)$ \\
\hline Period & $0.001(0.002)$ & $-0.001(0.002)$ & $0.003(0.002)$ \\
\hline Female & $0.041(0.034)$ & $0.032(0.035)$ & $0.043(0.038)$ \\
\hline Session dummies & yes & yes & yes \\
\hline $\mathrm{N}$ (by category) & $6094(403-2889-2802)$ & $4438(340-1746-2352)$ & $1882(135-1297-450)$ \\
\hline $\mathrm{Nb}$ of clusters & 375 & 375 & 159 \\
\hline Log Pseudolik. & -4493.249 & -3354.998 & -1265.501 \\
\hline Wald Chi2 & 2250.59 & 729.05 & 198.49 \\
\hline Prob $>$ Chi 2 & 0.0000 & 0.0000 & 0.0000 \\
\hline Pseudo- $\mathrm{R}^{2}$ & 0.172 & 0.160 & 0.146 \\
\hline
\end{tabular}


Table A6. Determinants of the ingratiation index - Tobit models with robust standard errors clustered at the first mover level, with Policy treatments

\begin{tabular}{|c|c|c|c|}
\hline $\begin{array}{l}\text { Dependent variable: } \\
\text { Ingratiation index }\end{array}$ & $\begin{array}{l}\text { Ingratiation and } \\
\text { random treatments } \\
(1)\end{array}$ & $\begin{array}{l}\text { Ingratiation } \\
\text { treatment } \\
(2) \\
\end{array}$ & $\begin{array}{l}\text { Random } \\
\text { treatment } \\
(3) \\
\end{array}$ \\
\hline Ingratiation treatment (initial) & $0.469^{* * *}(0.056)$ & - & - \\
\hline Ingratiation - No Noise & $0.409 * *(0.189)$ & $-0.140(0.266)$ & - \\
\hline Ingratiation - Cost & $-0.215(0.204)$ & $-0.619 * * *(0.191)$ & - \\
\hline Ingratiation - Incentives & $0.536 * *(0.244)$ & $-0.004(0.166)$ & - \\
\hline Random - Cost & $-1.150 * * *(0.231)$ & - & $-1.563 * * *(0.318)$ \\
\hline Performance & $-0.023(0.018)$ & $-0.035 *(0.019)$ & $0.007(0.042)$ \\
\hline Perf. in Ingratiation - No Noise & $0.056(0.041)$ & $0.066^{*}(0.040)$ & - \\
\hline Strength of the initial opinion & $-0.031 * * *(0.008)$ & $-0.027 * * *(0.007)$ & $-0.048 * * *(0.017)$ \\
\hline Initial opinion difference & $0.029 * * *(0.002)$ & $0.032 * * *(0.002)$ & $0.021 * * *(0.005)$ \\
\hline Squared initial difference & $-0.0003 * * *(<0.001)$ & $-0.0003 * * *(<0.001)$ & $-0.0002 * * *(<0.001)$ \\
\hline Topic: painting & $0.033(0.027)$ & $0.027(0.029)$ & $0.069(0.065)$ \\
\hline Topic: migration & $0.195^{* * * *}(0.042)$ & $0.188 * * *(0.043)$ & $0.244 * *(0.104)$ \\
\hline Negative initial diff.*migration & $-0.178 * * *(0.055)$ & $-0.170 * * *(0.056)$ & $-0.236^{*}(0.140)$ \\
\hline Topic: carbon tax & $0.058(0.041)$ & $0.067 \#(0.041)$ & $0.027(0.106)$ \\
\hline Negative initial diff.* carbon tax & $-0.077(0.055)$ & $-0.085(0.058)$ & $-0.056(0.135)$ \\
\hline Order & $0.092 *(0.054)$ & $-0.012(0.209)$ & $-0.144(0.216)$ \\
\hline Period & $0.004(0.003)$ & $0.004(0.003)$ & $0.008(0.008)$ \\
\hline Female & $0.043(0.055)$ & $0.013(0.055)$ & $0.162(0.114)$ \\
\hline Session dummies & yes & yes & yes \\
\hline Constant & $-0.547 * * *(0.167)$ & $-0.048(0.255)$ & $-0.361(0.243)$ \\
\hline $\mathrm{N}$ & 5699 & 4010 & 1689 \\
\hline Left-censored obs. & 2897 & 1658 & 1239 \\
\hline Right censored obs. & 535 & 464 & 71 \\
\hline $\mathrm{Nb}$ of clusters & 375 & 375 & 159 \\
\hline Log-pseudolikelihood & -4750.003 & -3262.138 & -1035.176 \\
\hline $\mathrm{F}$ & 13.59 & 11.70 & 5.29 \\
\hline Prob $>F$ & 0.000 & 0.000 & 0.000 \\
\hline Pseudo $\mathrm{R}^{2}$ & 0.137 & 0.090 & 0.120 \\
\hline
\end{tabular}

Note: The data exclude the observations in which the first mover has the same initial opinion as the second mover and those in which the first mover increased his distance with the second mover. Robust standard errors are in parentheses. $*, * *$, and $* * *$ indicate significance at the $10 \%, 5 \%$ and $1 \%$ level, respectively. \# indicates significance at the $10.5 \%$ level. 

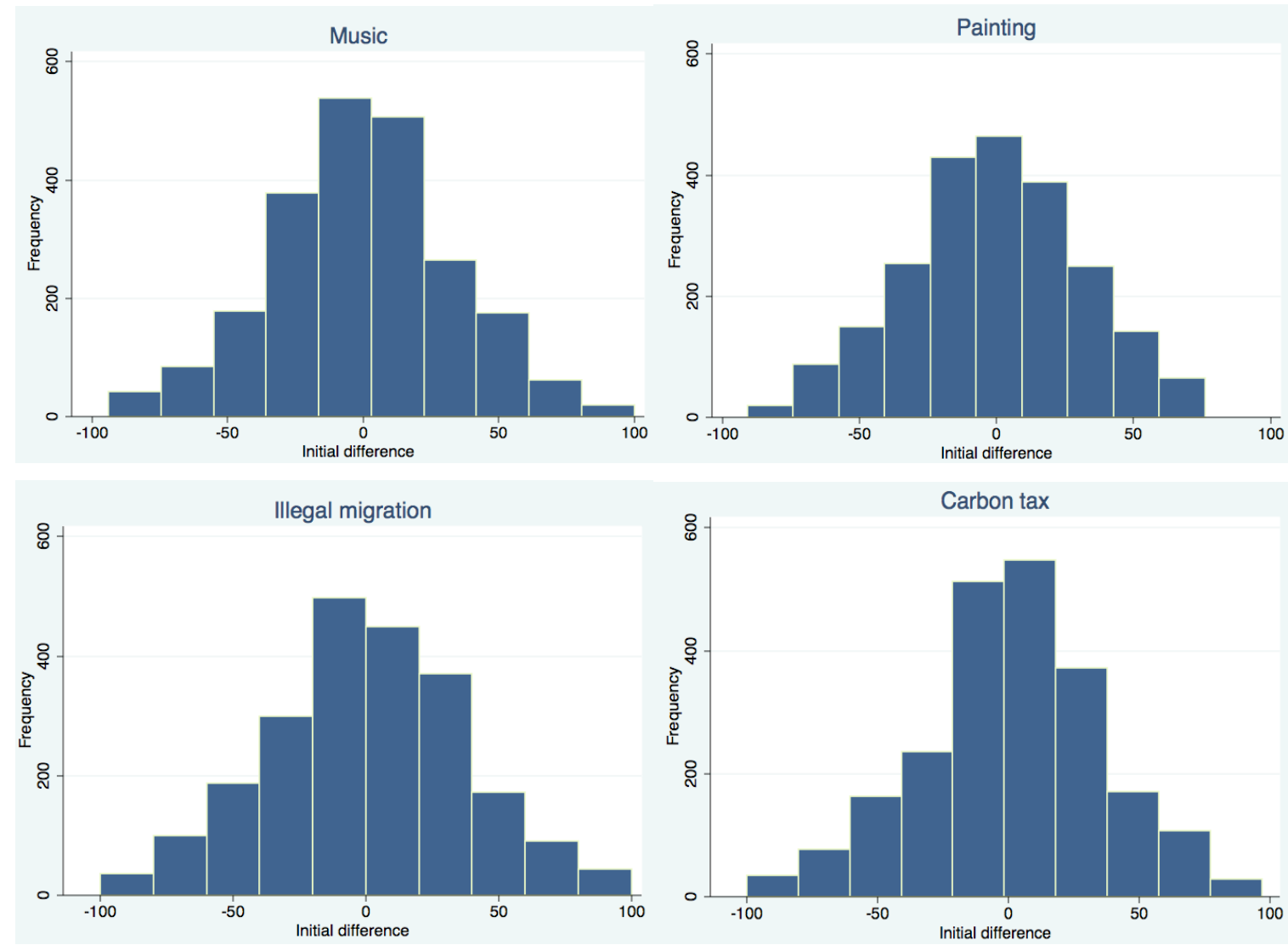

Figure 1A. Distribution of the frequency of differences in initial opinions between the first and the second movers, by topic, all treatments included 